\title{
The Molecular Dance of Fibronectin: Conformational Flexibility Leads to Functional Versatility
}

\section{Review Article}

Author(s):

Mezzenga, Raffaele; Mitsi, Maria

Publication date:

2019-01-14

Permanent link:

https://doi.org/10.3929/ethz-b-000317612

Rights / license:

In Copyright - Non-Commercial Use Permitted

Originally published in:

Biomacromolecules 20(1), https://doi.org/10.1021/acs.biomac.8b01258 
Raffaele Mezzenga*, Maria Mitsi*

6 ABSTRACT

7 Fibronectin, a large multimodular protein and one of the major fibrillar components of the extracellular 8 matrix, has been the subject of study for many decades and plays critical roles in embryonic development

9 and tissue homeostasis. Moreover, fibronectin has been implicated in the pathology of many diseases, 10 including cancer, and abnormal depositions of fibronectin have been identified in a number of amyloid and I1 non-amyloid lesions. The ability of fibronectin to carry all these diverse functionalities is through 12 interactions with a large number of molecules, including adhesive and signaling cell surface receptors, other 13 components of the extracellular matrix, and growth factors and cytokines. The regulation and integration 14 of such large number of interactions depends on the modular architecture of fibronectin, which allows a 15 large number of conformations, exposing or destroying different binding sites. In this review, we 16 summarize the current knowledge regarding the conformational flexibility of fibronectin, with an emphasis 17 on how it regulates the ability of fibronectin to interact with various signaling molecules and cell-surface 18 receptors and to form supramolecular assemblies and fibrillar structures.

$20 \quad$ Introduction 
Fibronectin is a secreted glycoprotein found in a soluble form circulating in plasma and in an insoluble

fibrillar form incorporated in the extracellular matrix of almost every cell type, where it functions as a major substrate for cell adhesion and migration ${ }^{1}$. Plasma fibronectin is produced by hepatocytes and it can become incorporated into extracellular matrices, both in vitro and in vivo ${ }^{2}$. Fibronectin has been implicated in a large number of physiological processes ${ }^{3}$, including blood coagulation $^{4}$, the uptake and consequent clearance of blood-borne particles and bacteria by phagocytic cells (opsonic activity) ${ }^{5}$, wound healing and tissue regeneration ${ }^{6}$, neovascularization ${ }^{7}$, and the orchestration of the complex morphogenetic movements during embryonic development ${ }^{8}$. Its importance for organogenesis and tissue homeostasis can be demonstrated by the fact that fibronectin null-mice die early during embryonic development due to severe cardiovascular defects ${ }^{9,10}$. On the other hand, abnormal depositions of fibronectin have been observed in a number of fibrotic diseases ${ }^{11,12}$ and amyloidoses ${ }^{13}$. Moreover, dysregulation of cell adhesion and migration on fibronectin has been implicated in tumor development and metastasis, and there is a large number of studies focusing on fibronectin as a cancer biomarker, as well as a therapeutic target ${ }^{14}$.

The history of fibronectin is of interest, as it was discovered multiple times through different routes, highlighting once again its wide range of functions. The first report of fibronectin (at the time called coldinsoluble globulin) dates 1948 , as a part of the first systematic study to fractionate the proteins of the plasma $^{15}$. However, it did not attract much attention, and it was not until the 1970s that studies for its purification and characterization were performed ${ }^{16}$, in parallel with independent studies of plasma proteins with opsonic activity ( $\alpha 2$-macroglobulin) ${ }^{17}$. At about the same time, research from a different direction identified insoluble proteins on the surface of cultured cells (named fibroblast surface antigen and large external transformation-sensitive protein), which were lost during oncogenic transformation and exhibited cell adhesive properties ${ }^{18,19}$. Gradually, it became evident that all of these diverse functions were performed by the same protein, sparking renewed interest in the research community. The protein was named fibronectin ${ }^{20}$, and, as has been noted by Jan McDonagh, it was 'transformed from a protein in search of a function to a protein with possibly too many functions ${ }^{21}$.

Intensive sequencing, biochemical and biophysical studies performed in the 1980s and 1990s to characterize fibronectin, yielded a wealth of information regarding its molecular architecture and possible 
modes of function. A picture of fibronectin as a multimodular protein, possessing many different binding

2 sites, and a significant degree of conformational flexibility emerged. Research during the last two decades,

3 taking advantage of the technological advances in molecular biology, imaging and structural techniques,

4 has provided further insights in the complexity of the structure and function of fibronectin, while new

5 functions continue to be revealed. Since its discovery more than 50 years ago, our ideas about fibronectin

6 have evolved: from a structural component keeping tissues together, it is now considered as a dynamic

7 molecule orchestrating the way biochemical and mechanical stimuli are presented to and interpreted by the

8 cells. However, despite decades of research, our understanding of the underlying molecular mechanisms

9 remains incomplete. This review aims at summarizing our current knowledge on the conformational

10 flexibility of fibronectin, with an emphasis on how it regulates the ability of fibronectin to interact with

I1 various signaling molecules and cell-surface receptors and to form supramolecular assemblies and fibrillar

12 structures, and to formulate open questions with the potential to drive the field forward.

$14 \quad$ Modular architecture and conformational flexibility

15 Fibronectin, isolated from both plasma and the extracellular matrix, is a large dimeric protein encoded 16 by one gene, and it is composed of two very similar but not identical polypeptide chains, each with a 17 molecular weight of $250-270 \mathrm{kDa}$, linked by two disulfide bridges near their C-termini in an antiparallel 18 fashion ${ }^{22}$. One of the prominent features of fibronectin is its ability to bind to cells through specific cell19 surface receptors (integrins) $)^{23}$, as well as to a large number of other biomacromolecules, including 20 collagen $^{24}$, heparin ${ }^{25}$, fibrin ${ }^{26}$, and even $\mathrm{DNA}^{27}$. These binding capacities can be localized in distinct 21 functional domains that can be released as stable fragments by proteolysis, suggesting a modular 22 architecture ${ }^{28}$. Indeed, spectroscopic, calorimetric and denaturation studies ${ }^{29-32}$ of both intact fibronectin 23 and its fragments showed that it is composed of a large number of independent structural modules, classified 24 into three different categories based on sequence homology: type I, type II, and type III. Later structural 25 studies have shown that each module has a consensus fold, with antiparallel $\beta$-strands of a well-defined 26 topology ${ }^{33}$. Each fibronectin chain is composed of 12 type I, 2 type II and at least 15 type III modules, 27 connected via loops of various sizes, flexibilities and orientations. Alternative splicing can result in the 
1 inclusion of one or two additional type III modules (termed EDA and EDB), or of a variable sequence

2 (known as V or IIICS), accounting for the variability observed between the two fibronectin chains, as well

3 as between plasma and cellular fibronectin ${ }^{34}$. The independent functional units along the fibronectin chain,

4 which exhibit distinct binding capacities and the ability to be released by proteolytic digestion without

5 structure or function loss, are formed by groups of different modules ${ }^{33}$. The major fibronectin functional

6 domains are summarized in Figure 1, although additional subdivisions are possible. Starting from the N-

7 terminus, $\mathrm{I}_{1}-\mathrm{I}_{5}$ binds to heparin and fibrin; it also interacts with bacteria, contains a major transglutaminase

8 cross-linking site and is critical for the incorporation of fibronectin into the fibrillar extracellular matrix. $\mathrm{I}_{6^{-}}$

$9 \quad \mathrm{I}_{9}$ forms the collagen/gelatin binding domain. Modules $\mathrm{III}_{2}-\mathrm{III}_{11}$ are traditionally considered as the cell-

10 binding domain, although the major integrin binding sites have been localized in $\mathrm{III}_{9}-\mathrm{III}_{10}$ and the remaining

I1 modules are involved in fibrillogenesis. $\mathrm{III}_{12}-\mathrm{III}_{15}$, also known as Hep2, is the major heparin-binding site of

12 fibronectin, contains additional integrin binding sites, and is a promiscuous binding site for a multitude of

13 growth factors. $\mathrm{I}_{10}-\mathrm{I}_{12}$ is the second fibrin-binding site of fibronectin.

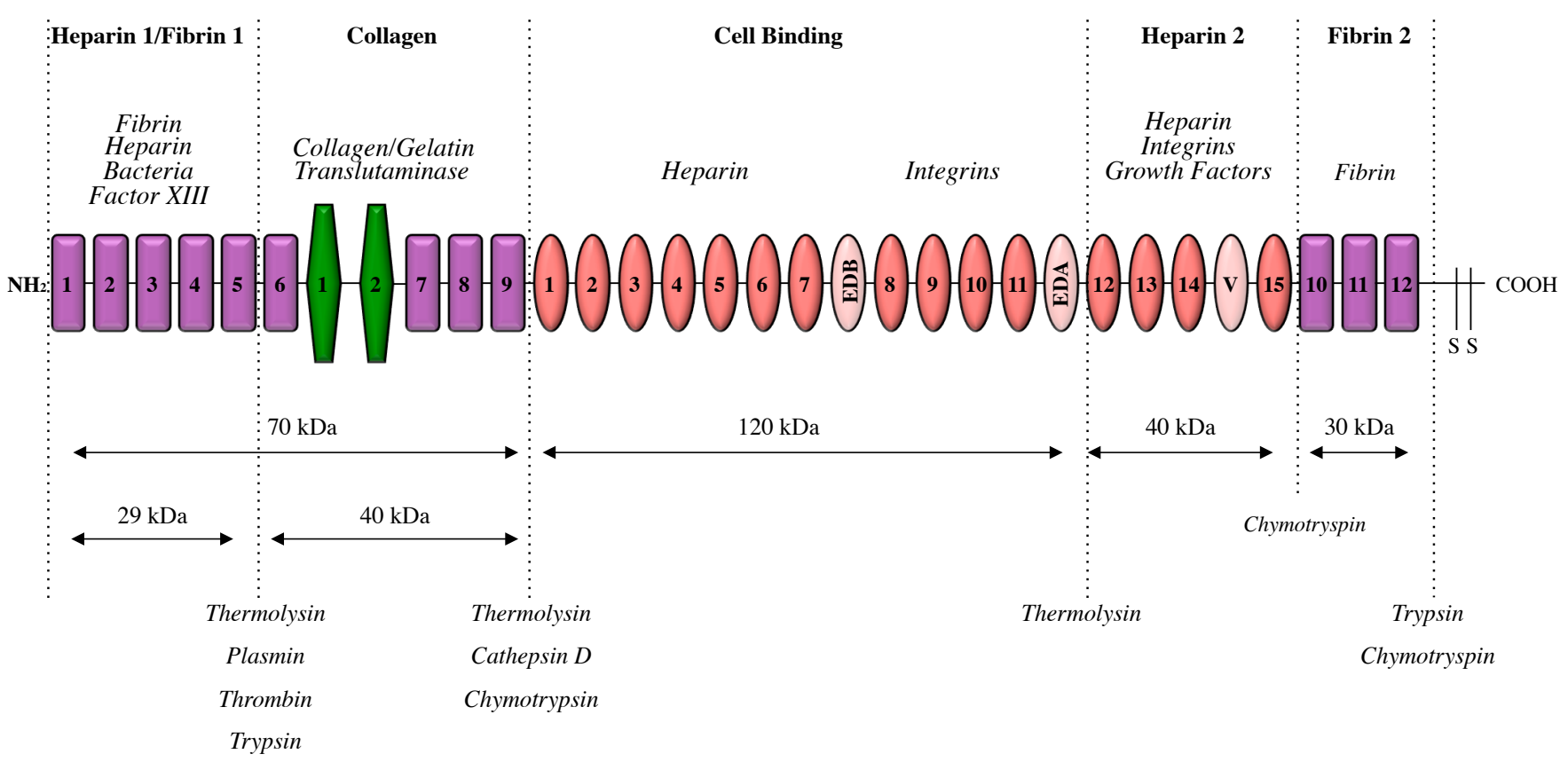

I6 Figure 1. The multimodular architecture of fibronectin. Schematic representation of modules type I

17 (purple), type II (green) and type III (red) constituting one chain of fibronectin. The alternatively spliced 
1 type III modules EDA and EDB, as well as the alternatively spliced region V are shown in a lighter color.

2 The disulfide bridges linking the two chains at their C-termini in an antiparallel fashion are also shown.

3 Several modules are forming functional domains displaying distinct binding affinities, and they can be

4 released as stable fragments by proteolysis. The major proteolytic sites and the respective proteases are

5 shown, together with the molecular weights of the resulting fragments (bottom), and some of their binding

6 affinities (top).

I0 overlapping and progressively shorter fragments spanning the major fibronectin functional domains,

11 differential scanning calorimetry (DSC) studies ${ }^{35-37}$ identified strong interactions between several adjacent

12 modules: $\mathrm{I}_{2}-\mathrm{I}_{3}, \mathrm{I}_{4}-\mathrm{I}_{5}, \mathrm{II}_{1}-\mathrm{II}_{2}, \mathrm{III}_{4}-\mathrm{III}_{5}, \mathrm{III}_{8}-\mathrm{III}_{9}, \mathrm{III}_{13}-\mathrm{III}_{14}$, as well as between non-adjacent modules: $\mathrm{I}_{6}-\mathrm{I}_{7}, \mathrm{III}_{3^{-}}$

$13 \mathrm{III}_{6}$ and $\mathrm{III}_{7}-\mathrm{III}_{9}$. Such interactions can be stabilizing or destabilizing for the individual modules. For

14 example, $\mathrm{III}_{8}$ is stabilized by its interactions with $\mathrm{III}_{9}$ (increased melting temperature), whereas $\mathrm{III}_{7}$ is 15 destabilized by $\mathrm{III}_{9}$ (decreased melting temperature ${ }^{36}$. The molecular components of such underlying 16 interactions are not known, as is their functional significance. It is interesting to note however, that these 17 arrangements result in an alternating pattern of thermostable and thermolabile structural units along the 18 fibronectin chain, at least for the regions $\mathrm{I}_{6}-\mathrm{I}_{9}$ and $\mathrm{III}_{2}-\mathrm{III}_{11}$. Solution nuclear magnetic resonance (NMR) 19 structures of module pairs have confirmed some of these interactions ${ }^{38-40}$, and provided evidence for 20 additional interactions, such as the one between $\mathrm{I}_{6}$ and $\mathrm{II}_{1}{ }^{41,42}$.

$21 \quad$ Sedimentation equilibrium studies and solid-phase binding assays have identified further interactions 22 between distal parts of fibronectin ${ }^{43}$. Some of these self-association sites can operate within one chain or 23 between chains, folding the fibronectin molecule upon itself and maintaining a compact configuration. It 24 has been postulated ${ }^{43}$ that interactions between modules $\mathrm{III}_{2}-\mathrm{III}_{3}$ from one chain with modules $\mathrm{III}_{14}-\mathrm{III}_{15}$ 25 from the other chain keep fibronectin in solution in a compact configuration. These interactions are 26 primarily electrostatic in nature, with $\mathrm{III}_{2}-\mathrm{III}_{3}$ having an excess negative charge and $\mathrm{III}_{12}-\mathrm{III}_{14}$ an excess 
positive charge, and they are significantly enhanced at low ionic strength ${ }^{43}$. Indeed, fibronectin adopts a more compact configuration in solutions of low ionic strength, a phenomenon that critically depends on the

3 presence of modules $\mathrm{III}_{12}-\mathrm{III}_{14}$. When these modules were removed or replaced with type III modules from tenascin, fibronectin adopted a much less compact conformation, which was no longer sensitive to the ionic strength $^{43}$.

When considering self-association sites within the fibronectin molecule, it is very important to keep in mind that the presence of neighboring modules can stabilize or destabilize certain interactions or impose additional constraints through distal interactions ${ }^{35,36}$. This can best be exemplified by the efforts to elucidate the structure of the collagen-binding domain of fibronectin $\left(\mathrm{I}_{6}-\mathrm{II}_{1}-\mathrm{II}_{2}-\mathrm{I}_{7}-\mathrm{I}_{8}-\mathrm{I}_{9}\right)$. Two independent studies of the $\mathrm{I}_{6}-\mathrm{II}_{1}$ module pair by solution $\mathrm{NMR}^{41,42}$ reported a weak interaction via a small intermodular interface, a flexible linker that does not appear to be involved in stabilizing or orienting the modules, and a significant degree of freedom, although a preferred orientation between the two modules was observed. Similarly, the pair $\mathrm{II}_{1}-\mathrm{II}_{2}$ showed no well-defined interface and a high degree of flexibility ${ }^{40}$. However, a completely different picture emerged from the structure of the slightly larger fragment $\mathrm{I}_{6}-\mathrm{II}_{1}-\mathrm{II}_{2}$ by solution $\mathrm{NMR}^{44}$. The limited interface between $\mathrm{I}_{6}$ and $\mathrm{II}_{2}$ was disrupted in the presence of the additional module. More strikingly, an extensive hydrophobic interface $\left(868 \AA^{2}\right.$ ) was observed between $\mathrm{I}_{6}$ and $\mathrm{II}_{2}$, giving a hairpin topology to the entire domain, which may increase accessibility to the domain $\mathrm{I}_{1}-\mathrm{I}_{5}$, facilitating fibrillogenesis. A very similar arrangement was observed by X-ray crystallography of the $\mathrm{I}_{6}-\mathrm{II}_{1}-\mathrm{II}_{2}-\mathrm{I}_{7}$ domain ${ }^{45}$, revealing a very compact pyramidal shape with $\mathrm{I}_{6}-\mathrm{II}_{1}-\mathrm{II}_{2}$ forming the base triangle and $\mathrm{I}_{7}$ the projecting tip, making contacts with both $\mathrm{I}_{6}$ and $\mathrm{II}_{2}$. The $\mathrm{I}_{6}-\mathrm{II}_{1}-\mathrm{II}_{2}$ modules in the crystal structure adopted a very similar structure as in solution but with a better-defined interface between $\mathrm{II}_{1}$ and $\mathrm{II}_{2}$. Yet, the crystal structure of the entire collagen-binding fragment $\left(\mathrm{I}_{6}-\mathrm{II}_{1}-\mathrm{II}_{2}-\mathrm{I}_{7}-\mathrm{I}_{8}-\mathrm{I}_{9}\right)$ showed a somewhat different picture ${ }^{46}$. A curved, elongated shape $(40 \times 40 \times 82 \AA)$ with the well-defined $\mathrm{I}_{6}-\mathrm{II}_{2}$ interface forming its $\mathrm{N}$-terminal lobe, module $\mathrm{II}_{1}$ at the center and modules $\mathrm{I}_{7}-\mathrm{I}_{8}-\mathrm{I}_{9}$ adopting a super-domain 8 -stranded antiparallel $\beta$-sheet configuration, forming the C-terminal lobe of the domain. In this structure, $\mathrm{I}_{8}$ exhibits significant deviations from the consensus type I fold. However, the high concentration of $\mathrm{Zn}^{2+}$ that was used as the crystallization agent may be responsible for the unusual arrangement of modules $\mathrm{I}_{7}-\mathrm{I}_{8}-\mathrm{I}_{9}$, as $4 \mathrm{Zn}$ atoms were observed interacting with 
$1 \quad \mathrm{I}_{8}$ in the crystal structure. Indeed, such rearrangements were not observed in the crystal structure of a

2 complex between isolated $\mathrm{I}_{8}-\mathrm{I}_{9}$ and collagen ${ }^{47}$. The physiological relevance of $\mathrm{Zn}^{2+}$ in regulating fibronectin

3 conformation and collagen binding is uncertain, although it demonstrates the capacity of $\mathrm{I}_{8}$ to undergo

4 drastic conformational changes.

5 The nature of the intermodular interactions regulating the structure of fibronectin in solution is complex

6 and highly dynamic. Factors such as pH, ionic strength, glycerol, heparin, mechanical stretching and

7 adsorption at surfaces of different chemistries, can affect fibronectin conformation ${ }^{43,48-51}$. This suggests the

8 possibility that fibronectin has the ability to adopt many different configurations between a compact and a

9 fully extended structure, supported by intermodular interfaces of different flexibilities and distal

10 interactions that introduce deviations from a strictly linear end-to-end modular arrangement ${ }^{52,53}$. Thus,

L1 different modules can be brought together through conformational changes to regulate not only the global

12 shape of the molecule but also its functionality: cryptic binding sites can be exposed, existing binding sites 13 destroyed, and new binding sites formed.

\section{Interactions between fibronectin and heparin}

16 As we will discuss in detail in this review, the linear polysaccharide chains of heparin and heparan 17 sulfate are components of the extracellular microenvironment with the ability to influence 18 fibronectin conformation and function. Heparan sulfate chains are covalently attached to proteoglycans, 19 a large family of proteins found either cell-surface bound or secreted in the extracellular matrix ${ }^{54}$. Heparin 20 on the other hand, is not attached to any proteoglycans but is secreted exclusively by mast cells, $21 \quad$ specialized cells of the immune system, which often accumulate in areas of tissue injury ${ }^{55,56}$. Heparin 22 shares the same backbone structure with heparan sulfate but exhibits a higher degree of sulfation, and is 23 often used as a model of heparan sulfate to identify heparan sulfate binding sites on proteins ${ }^{57}$. Prior to 24 discussing the effect of heparin/heparan sulfate on fibronectin conformation, this chapter will focus on the 25 complex interactions between heparin and fibronectin, involving multiple binding sites, which are 26 themselves subject to conformational regulation, yielding results that are sometimes conflicting and 27 difficult to interpret, as we discuss below. 
There are at least three heparin-binding sites on fibronectin: Hep1 at the N-terminal part of the molecule $\left(\mathrm{I}_{1}-\mathrm{I}_{5}\right)$, Hep2 at the C-terminal $\left(\mathrm{III}_{12}-\mathrm{III}_{14}\right)$, and Hep3 at the central part of the molecule (III ${ }_{4-}$ $\mathrm{III}_{6}$ ). Solid-phase binding assays ${ }^{58,59}$, as well as binding in solution ${ }^{60}$, have shown that Hep2 exhibits a very strong affinity for heparin, whereas Hep1 is only weakly bound. Moreover, heparin binding to Hep1 is inhibited by $\mathrm{Ca}^{2+}$, whereas that on Hep2 is $\mathrm{Ca}^{2+}$-insensitive ${ }^{61}$. Hep3 also shows low affinity for heparin ${ }^{62}$. Thus, Hep2 is considered the major heparin-binding site of fibronectin.

However, quantitative studies have shown that the actual affinity of Hep2 for heparin is rather low: a dissociation constant $\mathrm{K}_{\mathrm{d}}$ of $\sim 5 \mu \mathrm{M}$ was determined by plasmon surface resonance (SPR) on immobilized heparin ${ }^{63}$. A similar $K_{d}$ value $(\sim 2 \mu \mathrm{M})$ was reported for the interaction of heparin with full-length fibronectin in solution by fluorescence polarization measurements ${ }^{62}$. The stoichiometry of the interaction identified in this study was 2 heparin binding sites per Hep2 domain (4 heparin sites on a fibronectin dimer). However, mapping the heparin binding sites on fibronectin by singlemolecule AFM using colloidal gold conjugated to heparin ${ }^{64}$ showed, somewhat unexpectedly, that the majority of heparin binding events occurred close to the N-terminus, suggesting that under these conditions, Hep1 bound heparin stronger than Hep2. Similarly, a study of the mechanical properties of the heparin-fibronectin interactions by single-molecule dynamic spectroscopy 65 showed one major type of fibronectin-heparin interactions (i.e., one binding site) but with several fibronectinheparin pairs forming simultaneously. The fact that the binding events were $\mathrm{Ca}^{2+}$ sensitive points to the Hep1 being the binding partner.

These conflicting data concerning the affinity of the various heparin binding sites of fibronectin could be reconciled if one considers the possibility that the heparin binding sites themselves are subject to conformational regulation. Studies from one of the authors ${ }^{66}$ have shown that binding assays immobilizing heparin or fibronectin do not yield equivalent results. Whereas the entire amount of soluble fibronectin can be precipitated by heparin-agarose, immobilized fibronectin possesses very few heparin binding sites ( $\sim 1$ bound heparin molecule per 20 fibronectin molecules) but of high affinity $\left(\mathrm{K}_{\mathrm{d}} \sim 20 \mathrm{nM}\right)$. The isolated Hep2 domain shows a similar behavior. The idea that 
1 the Hep2 binding site is not readily available for heparin binding on surface-adsorbed fibronectin

2 can also explain the results of the aforementioned AFM and single-molecule dynamic spectroscopy 3 studies. In both these studies, fibronectin most likely adopts an extended configuration, through 4 adsorption on a hydrophilic surface ${ }^{64}$ or the use of a spacer to immobilize it on the AFM tip ${ }^{65}$, and is 5 able to bind heparin mostly via the Hep1 domain. On the other hand, when fibronectin adopts a more 6 compact configuration through adsorption on a hydrophobic surface, both Hep1 and Hep2 sites 7 appear to be blocked ${ }^{66}$. Therefore, heparin binding to fibronectin is in general conformation 8 sensitive. Indeed, it was shown that in solid-phase binding assays, heparin binds more efficiently to 9 the isolated Hep2 domain than in a fusion construct between $\mathrm{III}_{8}-\mathrm{III}_{10}$ and Hep2, i.e., the neighboring 10 modules mask the heparin-binding site ${ }^{67}$.

11 Heparin binding on Hep2 occurs primarily on module $\mathrm{III}_{13}{ }^{68}$, although some studies have shown 12 that $\mathrm{III}_{14}$ also contributes to the interaction ${ }^{69}$. Inclusion of the alternatively spliced EDA and $\mathrm{V}$ regions 13 to the $\mathrm{N}$ - and C-terminal of Hep2 respectively, does not interfere with heparin binding ${ }^{69}$. However, 14 peptides isolated from $\mathrm{III}_{13}$ containing the critical sequences with heparin-binding capacity often fail 15 to bind heparin ${ }^{70,71}$. It has been proposed that the spatial arrangement of these residues is very 16 important for determining heparin binding and affinity ${ }^{70,72}$. Indeed, the basic residues on III $_{13}$ are 17 clustered into a cationic 'cradle', whose spatial arrangement is the essential factor for heparin 18 binding 72 . Supporting this hypothesis is the observation that although III $_{14}$ is more basic than III $_{13}$, 19 its affinity to heparin is very low, correlating with a wider distribution of the basic residues over its 20 surface ${ }^{72}$. This further supports the hypothesis that heparin binding to Hep2 is conformation $21 \quad$ sensitive.

22 With respect to the requirements of heparin for binding to fibronectin, it was shown that the chain 23 size and its degree of $\mathrm{N}$-sulfation are critical determinants ${ }^{73}$. The effect of size seems to be more 24 important for the binding of small heparin oligosaccharides (2-6 kDa) to fibronectin, whereas for 25 heparin populations of higher molecular weight (5-30 kDa) did not play a role ${ }^{62}$. The prominent role 26 of N-sulfation has also been observed with heparan sulfate chains: domains of the chain that exhibit 
1 a high degree of sulfation (S-domains) bind strongly to fibronectin ${ }^{74-76}$. This last observation has

2 interesting implications concerning the physiological relevance of studies investigating heparin-

3 fibronectin interactions and their consequences for fibronectin structure and function. The results of

4 such studies may well reflect mechanisms operating in sites of mast cell accumulation, where heparin

5 secretion takes place, or alternatively, they may apply to local interactions between fibronectin and

6 the highly sulfated 'heparin-like' S-domains of heparan sulfate proteoglycans in the extracellular 7 matrix.

$9 \quad$ Heparin-mediated exposure of cryptic growth factor binding sites

10 AFM studies from one of the authors have shown that interactions between fibronectin and heparin 11 or heparan sulfate chains mediate a conformational change on fibronectin, from a compact to a more 12 extended configuration, which exposes cryptic Vascular Endothelial Growth Factor (VEGF) binding 13 sites on Hep2 ${ }^{77}$. For the sake of simplicity, we will use the term heparin instead of heparin/heparan 14 sulfate to describe this phenomenon. A similar heparin-mediated conformational change, which 15 exposed a specific antibody epitope on Hep2 while destroying another one, was observed by quartz 16 crystal microbalance with dissipation (QCMD) in a different study ${ }^{78}$. Moreover, this conformational 17 change reduces the affinity for heparin, leading to its dissociation and allowing it to diffuse and 18 interact with neighboring fibronectin molecules, altering their conformation as well. In this way, 19 substoichiometric amounts of heparin are sufficient to alter the conformation of a large number of 20 fibronectin molecules within the matrix, acting in a catalytic way (Figure 2 ) ${ }^{66}$. To our knowledge, this 21 is the only report of a macromolecule acting as a structural catalyst. According to this model, the open 22 conformation of Hep2 is thermodynamically more stable, but separated from the compact 23 configuration by a large kinetic energy barrier, associated with strong intermodular interactions. 24 Heparin binding interferes with these interactions, reducing the energy barrier, and facilitating the 25 transition to the open conformation ${ }^{66}$. Indeed, earlier calorimetric studies have shown that heparin 26 stabilizes the isolated $\mathrm{III}_{12}-\mathrm{III}_{14}$ modules, through breakage of the interactions between $\mathrm{III}_{12}$ and III $_{13}-$ 
$1 \quad \mathrm{III}_{14}{ }^{37}$. In fact, calorimetric studies have shown that interactions with heparin increase the melting

2 temperature of full-length fibronectin as well, exerting a stabilizing effect ${ }^{79}$.

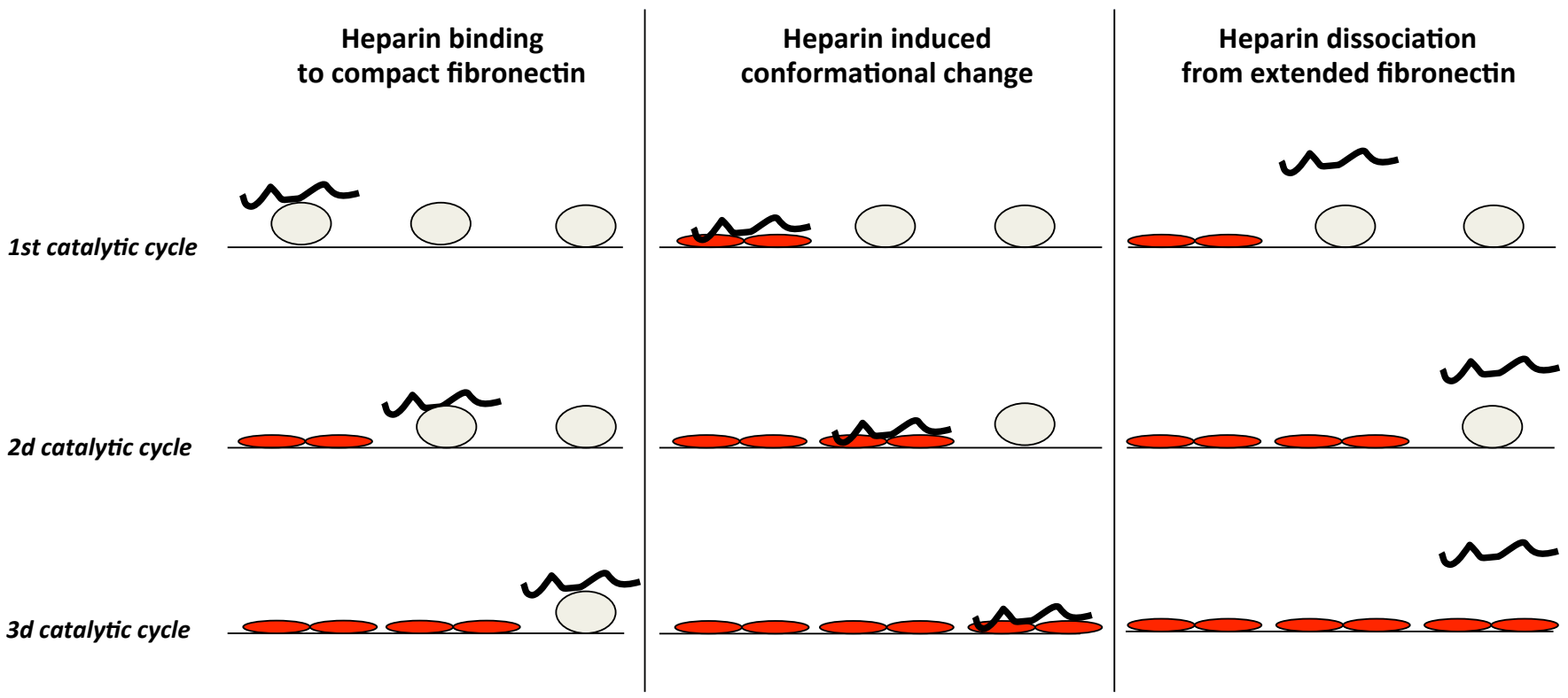

Figure 2. The catalytic mechanism of heparin altering fibronectin conformation. Interactions between

heparin (wavy line) and fibronectin induce a conformational change from a compact (gray) to an extended (red) configuration, which reduces the affinity for heparin, allowing for its dissociation, diffusion and binding to neighboring fibronectin molecules. In this way, substoichiometric amounts of heparin can alter the conformation of the entire fibronectin matrix, acting as a structural catalyst. Three catalytic cycles are shown. One of the functional consequences of the heparin-catalyzed conformational change on fibronectin is the exposure of cryptic growth factor binding sites on the Hep2 $\left(\mathrm{III}_{12}-\mathrm{III}_{14}\right)$ domain of fibronectin ${ }^{66}$.

The binding site exposed on Hep2 by the effect of heparin can be recognized by several members and

13 isoforms of the VEGF family, but not by Epidermal Growth Factor (EGF) or Fibroblast Growth Factor 14 (FGF)-2 $2^{77}$. However, the open Hep2 binds stronger Platelet-Derived Growth Factor (PDGF)-AA, and 15 enhances its potential to direct mesoderm migration during embryonic development ${ }^{80}$. An SPR study ${ }^{81} u \operatorname{sing}$ 16 immobilized modules $\mathrm{III}_{12}-\mathrm{III}_{14}$ showed that this domain of fibronectin has a remarkable ability to bind to 17 a large number of growth factors: several members of the VEGF, PDGF, FGF, Bone Morphogenetic Protein 
(BMP), Nerve Growth Factor (NGF), and Insulin Growth Factor Binding Protein (IGFB) families,

2 Transforming Growth Factor (TGF)- $\beta 1$, Heparin-binding EGF (HB-EGF), Hepatocyte Growth Factor

3 (HGF), and Connective Tissue Growth Factor (CTGF). Not all of these growth factors share the same

4 binding site on $\mathrm{III}_{12}-\mathrm{III}_{14}$, as suggested by cross-competition experiments. Moreover, treatment of $\mathrm{III}_{12}-\mathrm{III}_{14}$ with heparin increases the binding of some but not all growth factors, in full agreement with the results of the study demonstrating the catalytic action of heparin on fibronectin ${ }^{77}$. Based on these observations, we

7 hypothesize that regulatory mechanisms must exist that control the presentation of specific growth factor 8 binding sites on the Hep2 domain of fibronectin, relying, at least partly, on the conformational flexibility 9 of fibronectin and the ability of heparin to catalyze local structural rearrangements on this domain.

11 and biological output. Indeed, binding of IGFBP-5 ${ }^{82}$, IGFBP-3 ${ }^{83}, \mathrm{HGF}^{84}, \mathrm{CTGF}^{85}$ and VEGF VE $^{86}$ to 12 fibronectin, and particularly to the Hep2 domain, enhances or at least regulates their activity. This can be 13 partly explained by indirect effects, such as sequestration in the matrix that alters their bioavailability and 14 generates gradients that influence the cellular response ${ }^{87,88}$, but alternative, not necessarily mutually 15 exclusive, mechanisms could also play a role. Matrix-bound growth factors could alter their cognate 16 receptor trafficking, recruit co-receptors that alter their signaling output, or induce a distinct receptor 17 conformation that activates different signaling pathways. For example, it has been shown that immobilized 18 VEGF at the same effective amounts as soluble VEGF and without the formation of gradients activates 19 distinct downstream signaling pathways ${ }^{89,90}$. Deciphering the mechanisms via which fibronectin in the 20 extracellular matrix regulates the signaling potential of growth factors will have an impact not only for $21 \quad$ basic science but also for therapeutic and tissue engineering applications.

22 Although Hep2 has been recognized as a promiscuous growth factor binding domain of fibronectin, 23 additional domains have been identified that interact with specific growth factors. HGF can also bind at the 24 N-terminal domain of fibronectin $\left(\mathrm{I}_{1}-\mathrm{I}_{9}\right)^{84}$ and PDGF-BB interacts with both the Hep2 and with module $\mathrm{III}_{1}{ }^{91}$. Notably, $\mathrm{III}_{1}$ contains two binding sites for PDGF-BB in its C-terminal sequence ${ }^{92}$. Hep2 also contains two PDGF-BB binding sites, which share sequence similarity with these on $\mathrm{III}_{1}{ }^{92}$. These PDGF-BB binding 
1 sites on fibronectin are critical for fibroblast survival ${ }^{91-93}$. It will be interesting to investigate whether these

2 sites are able to bind other growth factors as well.

3 It should be noted that the extension of the Hep2 fibronectin domain by heparin and the ensuing exposure

4 of certain growth factor binding sites cannot be induced by mechanical forces, although the heparin-

5 mediated conformational change can be modulated by the extent of fibronectin stretching (Mitsi M.,

6 unpublished data). Similarly, mechanical forces could not expose a certain heparin-induced antibody

7 epitope on Hep2 but stretching reduced the heparin effect ${ }^{78}$. This demonstrates the exquisite specificity and

8 intricacy of the mechanisms that regulate fibronectin conformation and offers an explanation of how a

9 single domain of fibronectin can sustain so many different binding capacities in a functional way.

10 Furthermore, different parts of fibronectin, and the binding sites therein, may be differentially susceptible

L1 to biochemical or mechanical factors. Indeed, the N-terminal part of fibronectin $\left(\mathrm{I}_{1}-\mathrm{III}_{1}\right)$ seems to be

12 particularly prone to stretch-induced conformational changes: the binding sites for bacterial adhesins ${ }^{94}$ and

13 collagen ${ }^{95}$, as well as a specific antibody epitope on $\mathrm{I}_{9}-\mathrm{III}_{1}{ }^{96}$, are destroyed upon stretching, whereas the

14 self-association with the $\mathrm{N}$-terminal fragment of fibronectin $\left(\mathrm{I}_{1}-\mathrm{I}_{9}\right)$ is enhanced upon stretching ${ }^{96}$. Moreover,

15 a recent study from one of the authors has identified a binding site for the cytokine Interleukin (IL)-7 on

16 the N-terminal domain of fibronectin, which interacts stronger with IL-7 upon fibronectin stretching ${ }^{97}$.

$18 \quad$ Conformation-sensitive fibronectin-integrin interactions

19 Fibronectin exerts its cell adhesive properties by binding to integrins, a large family of 20 heterodimeric transmembrane cell-surface receptors, composed of two subunits, $\alpha$ and $\beta^{98}$. There 21 are at least 20 different $\alpha \beta$ combinations, each with distinct binding affinities for proteins of the 22 extracellular matrix and signaling properties. Although fibronectin recognizes at least 10 different 23 integrin heterodimers, $\alpha_{5} \beta_{1}$ is considered its major cell-surface receptor, responsible for a large 24 number of its functions, including fibrillogenesis ${ }^{23}$. As we will discuss in this section, the fibronectin25 integrin interactions are conformation sensitive: integrin binding requires a precise fibronectin 26 conformation, while it can itself cause conformational changes on fibronectin, altering the strength 27 of the interaction, as well as the intermolecular interface. 
The major integrin binding site on fibronectin contains the RGD sequence in module III $_{10}$, which is

2 located in a loop protruding from the main body of the module, exhibiting significant conformational

3 flexibility ${ }^{99,100 .}{ }^{15} \mathrm{~N}$ relaxation measurements show that this loop can undergo extensive movements

4 at the ps-ns time scale, although it appears relatively immobile at the $\mu$ s-ms time scale ${ }^{101}$. Thus, it can

5 search and dock at the appropriate integrin interface. In a crystal structure of III $_{10}{ }^{102}$, the RGD loop

6 appears disordered, in agreement with the hypothesis that it exhibits significant flexibility.

7 Although the RGD sequence is the main determinant of fibronectin-integrin interactions, early

8 studies identified a sequence N-terminal to RGD, which acts synergistically with RGD for $\alpha_{5} \beta_{1}$

9 binding ${ }^{103-105}$. This synergy site has been localized on $\mathrm{III}_{9}$ and its minimal sequence requirement is

10 the peptide PHSRN106,107. Whereas the RGD loop is recognized by both $\alpha_{5}$ and $\beta_{1}$ integrin subunits,

11 the synergy site binds mainly to the $\alpha_{5}$ subunit ${ }^{108-110}$. Thus, the two sequences act in a cooperative

12 manner to engage the integrin, and their positioning and relative orientation in fibronectin are

13 essential for determining the specificity and strength of the interaction. Solution NMR studies of III9-

14 III $_{10}$ showed a lack of a well-defined interface, as well as of a preferred orientation between the

15 modules, while ${ }^{15} \mathrm{~N}$ relaxation time measurements showed significant flexibility of the linker between

16 them at the ps-ns time scale ${ }^{111,112}$. Such interdomain flexibility would allow for movements that

17 would bring the RGD and synergy loops in the proper position for integrin binding. The crystal

18 structure of $\mathrm{III}_{7}-\mathrm{III}_{10}$, the first X-ray crystallographic study of linked type III modules ${ }^{113}$, revealed an

19 extended $140 \AA$ A long array, resembling a beads-on-a-string arrangement, with a pseudotwoflod 20 relationship between adjacent domains. The RGD loop was resolved in this structure because it was $21 \quad$ stabilized by crystal contacts. It protrudes from the structure and is free from contacts from the rest 22 of the molecule, and free to participate in integrin binding. The angles between modules vary; the 23 smallest is that between $\mathrm{III}_{9}$ and $\mathrm{III}_{10}\left(12^{\circ}\right)$, which brings the RGD and synergy loops in high 24 proximity. The interface between $\mathrm{III}_{9}$ and $\mathrm{III}_{10}$ is one of the smallest observed in fibronectin so far, 25 supporting the idea that it is a point of high flexibility along the fibronectin chain. 
Several observations suggest that both the flexibility of the RGD and synergy loops, as well as the

2 flexibility around $\mathrm{III}_{9}-\mathrm{III}_{10}$, are able to create multiple integrin-fibronectin interfaces, with distinct

3

4

5

6

functions. Firstly, not all integrins require the synergy site for binding to fibronectin ${ }^{114,115}$. In fact, differentially activated integrins will bind $\mathrm{III}_{9}-\mathrm{III}_{10}$ through distinct sites and with distinct strengths ${ }^{114,116}$. Indeed, mapping the synergy site by mutagenesis ${ }^{117}$ has shown that it includes a much more extensive interface than the originally proposed PHSRN peptide, which is widely distributed over the surface of $\mathrm{III}_{9}$, and can accommodate different binding interfaces. Interestingly, mutations in the synergy site that impair its functionality also impair its stability and folding ${ }^{118}$. This was rather unexpected as PHSRN lies on a solvent exposed loop. As $\mathrm{III}_{9}$ is chemically less stable than III $_{10}$, it was suggested that an additional role of the synergy site is to stabilize III9. Therefore, any factor which could increase the global stability of III9 would overcome the need for the synergy site for integrin recognition by fibronectin.

Moreover, mechanical forces transmitted through the actin cytoskeleton may act as a mechanical switch, transforming the $\alpha_{5} \beta_{1}$-fibronectin complex from a relaxed into a tensioned state ${ }^{119}$. The two states are characterized by distinct intermolecular contacts: the relaxed state depends primarily on RGD binding, whereas the tensioned state involves both the RGD and synergy sites. Mechanical unfolding may provide an additional level of conformational regulation of integrin-fibronectin binding. Steered molecular dynamics simulations ${ }^{120}$ support a hypothesis whereby mechanical forces can unfold $\mathrm{III}_{9}-\mathrm{III}_{10}$ in three sequential steps that change the distance and relative orientation between the two modules. The simulations predict that at low levels of stretch, a pre-stretched state occurs, in which the distance between PHSRN and RGD increases but is still sufficient for $\alpha_{5} \beta_{1}$ binding. At intermediate stretch levels, a de-coupled state further increases the distance between the two states and also changes their orientation, disrupting cooperative $\alpha_{5} \beta_{1}$ binding but still sustaining binding of individual integrins on the two sites. Finally, high levels of stretch result in a completely unfolded state, where both binding sites are destroyed. Thus, mechanically regulated fibronectin conformation could affect integrin binding, as well as the requirements for the synergy site. 
3 Many cell types have the ability to assemble exogenously added or endogenously produced

4 fibronectin into a fibrillar meshwork ${ }^{121}$, in a stepwise process that requires an intact actin 5 cytoskeleton and the ability of the cell to contract and apply tension ${ }^{122}$. Thus, newly assembled 6 fibronectin fibrils coalign with bundles of actin filaments in the cytoskeleton and with focal 7 adhesions ${ }^{123}$. Moreover, disruption of the actin cytoskeleton inhibits fibronectin matrix assembly ${ }^{124-}$ 8 126. At the same time, fibronectin fibrillogenesis depends on the interactions between $\alpha_{5} \beta_{1}$ and 9 fibronectin. Antibodies blocking either the RGD sequence on fibronectin ${ }^{127}$ or the $\alpha_{5} \beta_{1}$ integrin $^{128,129}$ 10 inhibit fibronectin incorporation into the matrix, localization of $\alpha_{5}$ into focal adhesions, and cell I1 adhesion. The essential element in this process is the ability of the integrin to engage its ligand, as 12 deletion of the cytoplasmic domain of $\alpha_{5}^{130}$ or substitution of it with that of other integrins ${ }^{131}$ has no 13 effect. During the early steps of fibronectin fibrillogenesis, $\alpha_{5} \beta_{1}$ bound to fibronectin translocates 14 from the cell periphery towards the cell center, pulling on the fibronectin molecules and induces fibril 15 formation ${ }^{132}$. Mapping the traction forces generated by the adherent cell showed a strong positive I6 correlation between the direction of the pulling force exerted by the cell and the direction of 17 fibronectin fibrillogenesis ${ }^{133}$. Furthermore, disruption of the cell contractile machinery decreases $18 \alpha_{5} \beta_{1}$-fibronectin interactions ${ }^{119}$. Thus, fibronectin matrix assembly is mechanically coupled to 19 fibronectin- $\alpha_{5} \beta_{1}$ interactions.

20 Fibronectin matrix assembly is a stepwise process consisting of an initiation and a growth phase. 21 During the initiation phase, fibronectin molecules bind to integrins and accumulate on the cell 22 surface. The molecular interaction dominating this process is the binding of RGD to $\alpha_{5} \beta_{1}$, which then 23 transmits the mechanical forces generated by the actin cytoskeleton to the fibronectin, causing 24 conformational changes and exposing self-association sites that allow fibril elongation and 25 maturation to proceed ${ }^{134}$. The primary self-association site on fibronectin is the N-terminal Hep1 26 domain, consisting of modules $\mathrm{I}_{1}-\mathrm{I}_{5}$, as constructs without it fail to incorporate into the matrix ${ }^{135}$. In 
1 soluble fibronectin, long-range interactions between $\mathrm{I}_{1}-\mathrm{I}_{5}$ and other regions of fibronectin, including

$2 \mathrm{III}_{1}-\mathrm{III}_{7}$, mask the self-association sites protecting the molecule from aggregation. However, upon 3 integrin pulling, conformational changes propagate throughout the molecule, unmask the self4 association sites, activate the $\mathrm{I}_{1}-\mathrm{I}_{5}$ assembly domain and allow for matrix assembly ${ }^{136}$. In fact, 5 addition of soluble Hep1 domain in cell culture can be incorporated into the matrix and can inhibit 6 fibronectin binding and consequently matrix assembly ${ }^{137,138}$. Another feature of the fibronectin 7 molecule that is absolutely necessary for fibril formation is its dimeric character: the C-terminal 8 peptide containing the disulfide bridges. Minimal fibronectin constructs containing $\mathrm{I}_{1}-\mathrm{I}_{5}$ and the C9 terminal peptide (termed deminectins) could form fibrils or incorporate into an existing fibronectin 10 matrix only as disulfide-bonded dimers ${ }^{135,139,140}$. The two phases of fibronectin matrix assembly can 11 be followed both biochemically and microscopically ${ }^{141}$. During the initiation phase of matrix 12 assembly, fibronectin binds reversibly to the cell surface and forms a molecular pool (pool I) from 13 which fibrils will form at the growth stage. The molecules in this pool are soluble to the detergent 14 deoxycholate, their electrophoretic mobility is indicative of single fibronectin molecules and at the 15 light microscopic level, they appear mainly as a punctate pattern with some very fine fibrils. Pool I of 16 cell surface-adsorbed fibronectin is then slowly transformed into a deoxycholate-insoluble matrix 17 (pool II), containing well-resolved fibrils at the light microscopic level. The fibronectin molecules in 18 pool II bind irreversibly and their electrophoretic mobility indicates a significant degree of 19 aggregation ${ }^{141}$.

20 Besides $\mathrm{I}_{1}-\mathrm{I}_{5}$ and the $\mathrm{C}$-terminal disulfide bridges, several other regions of fibronectin have been $21 \quad$ involved in fibrillogenesis, although they are not essential, in the sense that constructs lacking them 22 but containing the $\mathrm{I}_{1}-\mathrm{I}_{5}$, can still form fibrils ${ }^{135}$. These regions include $\mathrm{III}_{1}-\mathrm{III}_{2}{ }^{142-144}, \mathrm{III}_{4}-\mathrm{III}_{8}{ }^{143}$, and $23 \quad \mathrm{III}_{12}-\mathrm{III}_{14}{ }^{143,145}$. The involvement or requirement of these domains for matrix assembly has been 24 ascertained by using constructs lacking them or by blocking antibodies. However, the exact 25 interactions between fibronectin molecules within the fibers of the extracellular matrix are not 26 known. Although elements of periodicity have been reported in fibronectin fibrils, which are 
1 consistent with a model of staggered fibronectin molecules arranged in an antiparallel fashion, the

2 heterogeneity of the fiber population makes it difficult to identify the exact self-association sites ${ }^{146-}$

$3{ }^{150}$. A recent in silico study ${ }^{151}$ suggests that the existence of multiple binding sites within the type III

4 modules that can participate in self-assembling interactions between fibronectin molecules results

5 in more robust fibrillogenesis, with a heterogeneous fibril population, including small and large

6 fibers, that better resembles the cell-derived fibronectin matrix. Interestingly, the exact position of

7 these sites within fibronectin and the mechanical and chemical properties of their constituent

8 modules has very little influence in the resulting fibrillogenesis.

$10 \quad$ Heparin and matrix assembly

11 A recent study showed that fibronectin matrix assembly does not proceed in the absence of 12 heparan sulfate proteoglycans on the cell surface ${ }^{152}$. The ability of heparan sulfate chains to bind 13 multiple fibronectin molecules through the Hep2 domain seems to be a prerequisite for fibronectin 14 fibrillogenesis. These observations, taken together with the catalytic effect of heparin/heparan 15 sulfate on fibronectin conformation, suggest that besides the exposure of cryptic growth factor 16 binding sites, heparin/heparan sulfate may also expose self-association sites necessary for 17 fibrillogenesis. The first evidence for such an effect came from early studies of plasma 18 cryoprecipitation ${ }^{153}$. It was observed that heparin promotes the precipitation of fibronectin, 19 especially at low temperatures, leading to the formation of fibrillar material ${ }^{154}$. Fluorescence 20 polarization studies ${ }^{155}$ showed that a conformational change exposing self-association sites, and 21 leading to protein aggregation and ultimately to precipitation, takes place following weak but fast 22 interactions between fibronectin and heparin in solution.

23 Interestingly, all fibronectin self-association sites required for fibrillogenesis have heparin-binding 24 affinity, suggesting the intriguing hypothesis that the classical integrin-mediated fibrillogenesis 25 pathways may be linked in some level with interactions with heparin and/or heparan sulfate 26 proteoglycans. Indeed, a strong correlation between the heparin-binding capacity of the Hep2 
1 domain of fibronectin and its ability to mediate or modulate cell adhesion has been repeatedly

2 demonstrated for a large number of healthy and cancer cell types, including fibroblasts ${ }^{67,156-161,}$ 3 platelets $^{162}$, neural ${ }^{163}$, endothelial ${ }^{164,165}$, kidney ${ }^{159}$, corneal ${ }^{166}$, mammary epithelial ${ }^{167}$ and bone4 derived $^{168}$ cells, as well as melanoma $67,169-172$, neuroblastoma ${ }^{173,174}$, lung carcinoma ${ }^{67,175}$, 5 fibrosarcoma ${ }^{174}$, renal carcinoma ${ }^{174}$, squamous cell carcinoma ${ }^{176}$, osteosarcoma ${ }^{159}$, and colon 6 carcinoma ${ }^{177}$ cells. The mechanisms mediating cell adhesion and the observed phenotype are highly 7 dependent on the cell type, highlighting the complexity of the molecular interactions involving the 8 Hep2 domain. For melanoma cells ${ }^{169}$, neural cells ${ }^{163,173}$ and endothelial cells ${ }^{164}$, Hep2 alone is 9 sufficient to mediate cell adhesion, acting independently of the RGD domain. In the course of these 10 studies, it was found that Hep2 contains multiple adhesion sites (at least 7 distinct sites), some of 11 which recognize the heparan sulfate chains of proteoglycans on the cell surface, whereas others bind 12 to integrins different than $\alpha_{5} \beta_{1}$ (RGD-independent adhesion), and most frequently $\alpha_{4} \beta_{1} 170,173,178,179$. 13 It is possible that contiguous heparin- and integrin-binding sites on Hep2 bring the two adhesive 14 complexes together as a necessary step for cell adhesion ${ }^{163}$. However, in most cases, Hep2 acts 15 cooperatively with the RGD adhesion site. A very frequent observation is that cells may attach to 16 isolated RGD or Hep2, but they require both domains to fully spread and develop focal adhesions and 17 stress fibers. This depends either on proteoglycan binding or on integrin binding to 18 Hep2 $158,160,166,171,175,177$. It is interesting to note that addition of one domain (or even an isolated 19 peptide derived from each domain) in solution is sufficient to rescue the adhesive phenotype, 20 suggesting that the key feature is the co-activation of the two complexes and not their spatial 21 distribution. However, minimal fusion constructs containing the two domains, such as $\mathrm{III}_{8}-\mathrm{III}_{10}+\mathrm{III}_{12^{-}}$ $22 \mathrm{III}_{14}{ }^{174}$ and $\mathrm{III}_{7}-\mathrm{III}_{10}+\mathrm{III}_{13}{ }^{159}$, often work as well as full-length fibronectin, whereas adsorption of 23 domain mixtures does not. This speaks for the theory that requires a certain spatial orientation of 24 the two adhesive complexes and possibly an interaction between them in order to gain full function. 25 Moreover, as already mentioned above, the interactions with the heparin-binding sites of Hep2 seem 
1 to be conformation sensitive: several Hep2-derived peptides with heparin-binding capacity require

2 conjugation to a large carrier protein to exhibit full functionality ${ }^{157,163 .}$

3 These multiple adhesion mechanisms to one extracellular matrix protein may have a redundant 4 role, increasing the robustness of the cell response, or they may have different functions, for example,

5 fine-tuning the balance between adhesion (through $\alpha_{5} \beta_{1}$ ) and migration (through $\alpha_{4} \beta_{1}$ ). However,

6 the possibility that interaction of fibronectin with the heparan sulfate chains of the cell-surface 7 proteoglycans may be a necessary step to expose self-association sites necessary for fibrillogenesis

8 to occur suggests novel regulatory roles for proteoglycans on sites of adhesion and fibrillogenesis.

9 Future studies can determine whether this happens in concert with the well-documented RGD10 mediated mechanical unfolding of fibronectin that initiates fibrillogenesis or even required for it.

12 Fibronectin supramolecular assemblies and amyloids

13 The ability to undergo fibrillogenesis is one of the most prominent features of fibronectin. The majority 14 of fibronectin functions depends on its assembly into a fibrillar matrix through a complex cell-mediated 15 process $^{121}$. However, several physical and chemical factors can promote the formation of fibrillar 16 fibronectin structures in the absence of cells, as summarized in Figure 3A. A common element between 17 these diverse mechanisms is the exposure of self-association sites, many of which are cryptic in order to 18 keep the molecule soluble, and they are exposed only upon appropriate stimulation. This can occur by 19 mechanical unfolding ${ }^{180-182}$, surface adsorption ${ }^{183-185}$, denaturation ${ }^{186}$ or proteolysis ${ }^{187}$ (the site can be 20 exposed in a fragment but remain masked in the context of the full-length molecule). Several type III 21 modules, including $\mathrm{III}_{12}-\mathrm{III}_{14}$ and $\mathrm{III}_{1}$, possess cryptic binding sites for the $\mathrm{N}$-terminal part of fibronectin $22 \quad\left(\mathrm{I}_{1}-\mathrm{I}_{5}\right)$, which, as already mentioned, may be involved in fibronectin fibrillogenesis ${ }^{121}$. It is therefore possible 23 that artificial fibronectin multimerization and fibrillar assembly may illuminate certain aspects of cell24 driven fibrillogenesis and matrix assembly. 


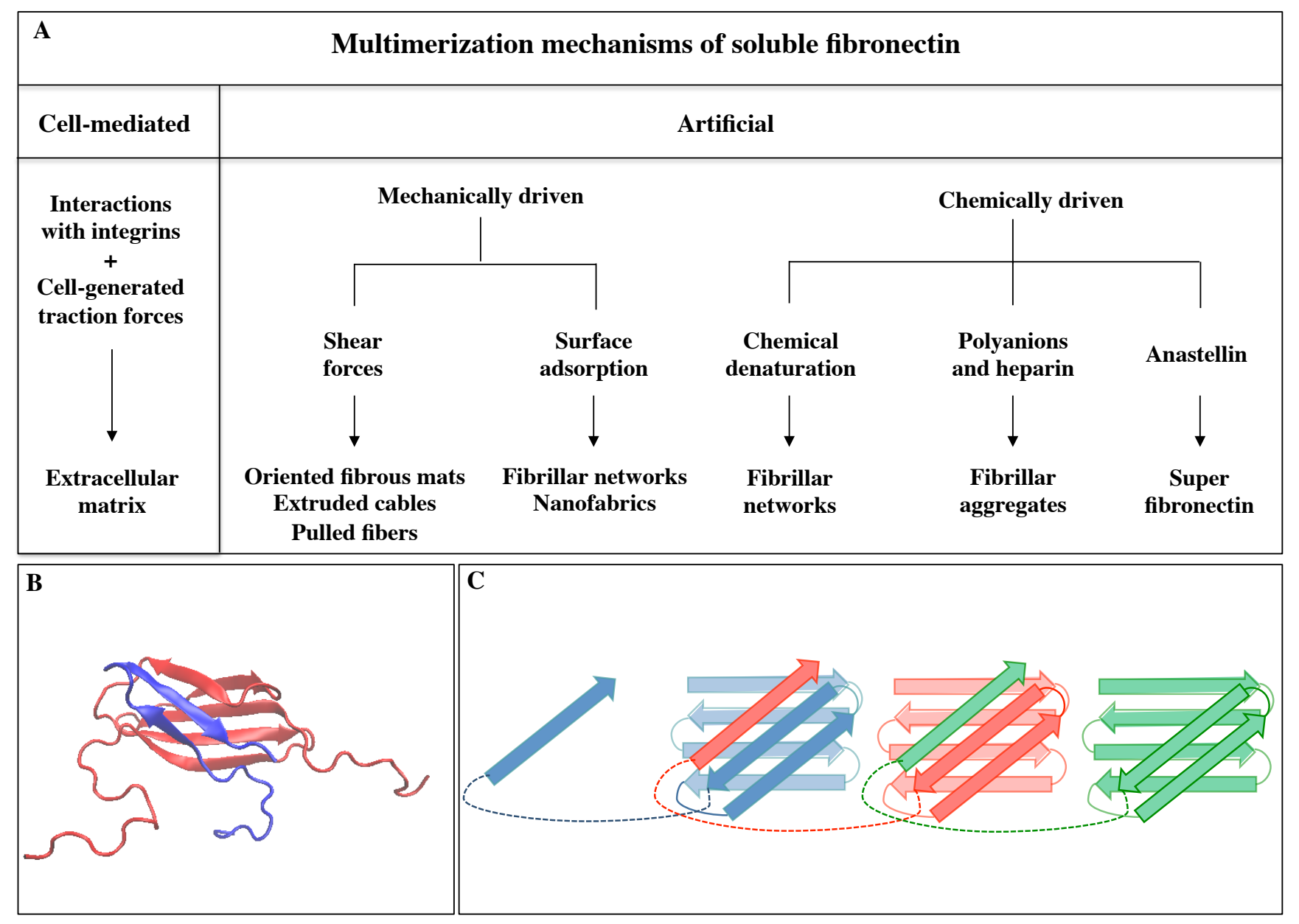

2 Figure 3. Fibronectin fibrillogenesis and multimerization. (A) The ability of fibronectin to undergo

3 fibrillogenesis is an inherent property of the molecule. During extracellular matrix assembly, cells drive

4 fibronectin fibrillogenesis by using a combination of biochemical fibronectin-integrin interactions and

5 traction forces ${ }^{44}$. However, the formation of fibrillar structures and networks can be promoted artificially,

6 by chemical or physical forces that can expose self-association sites on fibronectin molecules. Several of

7 such factors, including shear forces ${ }^{45-47}$, surface adsorption ${ }^{48,49}$, chemical denaturation ${ }^{51}$, and interactions

8 with polyanions ${ }^{209}$, heparin ${ }^{182}$ and peptides such as anastellin ${ }^{79}$ are listed, along with the fibrillar material

9 produced in each case. (B) High-resolution NMR structure of a complex between anastellin (blue) and

10 module III $_{1}$ of fibronectin (red), demonstrating the $\beta$-swapping mechanism: two $\beta$-strands from III $_{1}$ are

11 unfolded and substituted with the two $\beta$-strands from anastellin. (C) Schematic representation of a

12 hypothetical $\beta$-swapping mechanism that could support fibronectin fibrillogenesis. Type III modules from

13 different fibronectin molecules (each shown in a different color) interact with each other through a $\beta$ - 
1 swapping mechanism, with each module offering one $\beta$-strand. The connection of this $\beta$-strand with the

2 rest of the module is shown as a dashed line, drawn intentionally larger for clarity.

4 Cryptic self-association sites in $\mathrm{III}_{1}$ are largely responsible for fibronectin polymerization in the absence 5 of cells into a matrix termed super-fibronectin, which is related but functionally distinct from cell-derived 6 fibrillar fibronectin ${ }^{188}$. However, it has been proposed that super-fibronectin can restore the normal 7 fibronectin matrix, which is lost upon oncogenic transformation, as ex vivo treatment of tumor cells 8 with super-fibronectin or intraperitoneal administration of it inhibits tumor metastasis ${ }^{189}$. These 9 observations, suggesting similarities between cell-derived fibronectin fibrillogenesis and super10 fibronectin formation, prompted intensive studies to unravel the mechanism of super-fibronectin I1 formation. Consequently, a C-terminal peptide from III $_{1}$ was identified, which was sufficient to induce 12 super-fibronectin formation and possessed anti-angiogenic, anti-metastatic and anti-tumorigenic 13 properties when administered systemically ${ }^{190}$. Based on these properties, the peptide was termed 14 anastellin (from the Greek 'anastello', meaning 'to inhibit').

15 These functions of anastellin depend upon its ability to interact with fibronectin ${ }^{191}$. The binding 16 sites of anastellin on fibronectin have been localized on modules $\mathrm{III}_{1}-\mathrm{III}_{3}$ and $\mathrm{III}_{11}$, with modules $\mathrm{III}_{1}$ $17 \mathrm{III}_{3}$ being the primary binding site, able to interact with 3 anastellin molecules ${ }^{192}$. Solution NMR 18 studies of $\mathrm{III}_{3}$ showed that it has low chemical stability and a high unfolding rate constant compared 19 to other type III modules, suggesting its propensity to open up and expose $\beta$-strands that could 20 interact with anastellin ${ }^{193}$. Indeed, the solution NMR structure of a complex between $\mathrm{III}_{3}$ and $21 \quad$ anastellin showed two of the $\beta$-strands of $\mathrm{III}_{3}$ unfolded, possibly exposing further self-association 22 sites, and substituted in the complex by the two $\beta$-strands of anastellin ${ }^{194}$ (Figure 3B).

23 Anastellin can also induce super-fibronectin-like aggregates when interacting with the isolated 24 domain $\mathrm{III}_{1}-\mathrm{III}_{2}{ }^{195}$. For this to occur, the instability and consequent unfolding of $\mathrm{III}_{2}$ are essential. 25 These observations support a mechanism whereby spontaneous unfolding of the target sequences 26 allows anastellin binding and exposure of further self-association sites leading to fibrillogenesis. 
1 Interestingly, $\mathrm{I}_{1}-\mathrm{I}_{9}$ can be incorporated to the $\mathrm{III}_{1}-\mathrm{III}_{2} /$ anastellin aggregates, suggesting that

2 fibronectin fibrillogenesis in vivo (which depends on self-association sites on $\mathrm{I}_{1}-\mathrm{I}_{5}$ ) may follow a 3 similar mechanism with that underlying anastellin-induced fibrillogenesis. This can happen through

4 a $\beta$-strand swapping mechanism involving interactions between type III modules, where unfolding 5 of $\beta$-strands from one module offers binding sites for $\beta$-strands from neighboring modules (Figure $63 \mathrm{C}$ ). Although aggregation of the full-length $\mathrm{III}_{1}$ module does not occur spontaneously, inner $\beta$ 7 strands can become exposed upon partial denaturation, proteolysis, mutations or mechanical stress, 8 leading to fibrillogenesis in an anastellin-like manner ${ }^{196}$. However, additional mechanisms may be 9 involved, such as the formation of a tandem $\beta$-zipper between consecutive type III modules and $\mathrm{I}_{1}-\mathrm{I}_{5}$, 10 similar to the one observed upon binding of bacterial adhesins on $\mathrm{I}_{1}-\mathrm{I}_{5}{ }^{197}$.

11 Certain structural features of anastellin resemble those of amyloid precursors, namely the lack of $12 \beta$-strands normally found in the intact module, leading to the exposure of an extensive hydrophobic 13 surface able to mediate aggregation ${ }^{196}$. This raises the exciting possibility that some aspects of 14 fibronectin fibrillogenesis in vivo may resemble amyloid fibril formation, following not the classical $15 \beta$-sheet helix formation but through $\beta$-strand swapping. Further support for this hypothesis comes 16 from studies of III $_{9}$, another type III module with low chemical stability, which can undergo 17 spontaneous polymerization under physiological conditions through an inherently unstable, 18 partially unfolded intermediate, which exposes self-association sites ${ }^{198}$. The resulting fibrils exhibit 19 amyloid-like properties, and it was suggested that they are formed through $\beta$-strand swapping 198 . 20 Fibronectin fibrillogenesis based on the $\beta$-strand swapping mechanism has also been induced by a 21 $\quad$ III $_{10}$-derived peptide, which could become exposed upon integrin-mediated pulling on fibronectin in 22 physiological conditions ${ }^{199}$.

23 The idea that fibronectin can form amyloid-like fibrils merits further investigation for both its 24 physiological functions (matrix assembly and aggregation during blood clotting, wound healing and 25 tissue regeneration), as well as potential pathological repercussions (abnormal depositions in 26 fibrotic diseases and lesions). Recently, it was shown that plasma fibronectin can form amyloid-like 
aggregates upon thermal unfolding, which exhibit impaired binding capacity for gelatin and RGD

2 peptides 200 , but they are not cytotoxic and can regulate fibronectin matrix assembly, cell morphology and motility, and integrin distribution in healthy and cancer cells ${ }^{201}$.

The formation of amyloid-like $\beta$-sheet supramolecular structures during fibronectin multimerization is also supported by the crystallographic study of the collagen-binding domain of fibronectin in the presence of $\mathrm{Zn}^{2+}$, already discussed earlier ${ }^{46}$. In this study, a homodimer generated by a crystallographic twofold symmetry axis was observed, with a very extensive interface involving the super-domain $\beta$-sheet $\mathrm{C}$ terminal lobe of the fragment. Remarkably, residues from both protomers contribute to the $\mathrm{Zn}^{2+}$ binding site, suggesting that $\mathrm{Zn}^{2+}$ mediates dimerization. The $\mathrm{Zn}^{2+}$-induced homodimerization of the collagenbinding domain was also observed in solution ${ }^{46}$, strengthening the crystallographic observations. Intriguingly, $\mathrm{Zn}^{2+}$ promotes $\beta$-amyloid peptide $(\mathrm{A} \beta)$ aggregation, with possible implications for the pathogenesis of Alzheimer's disease ${ }^{202,203}$. Although the mechanism of $\mathrm{Zn}^{2+}$ is not entirely understood, there is a positive correlation between high concentrations of $\mathrm{Zn}^{2+}$ and $\mathrm{A} \beta$ aggregation both in vitro and in vivo ${ }^{204-}$ 207. Similar to the case of the collagen-binding domain of fibronectin, $\mathrm{Zn}^{2+}$ interacts with certain histidine residues in $\mathrm{A} \beta$, although the geometry of complexation is different ${ }^{208}$. Furthermore, in contrast to the effect on fibronectin structure, $\mathrm{Zn}^{2+}$ binding to $\mathrm{A} \beta$ decreases the overall content of $\beta$-sheet secondary structure elements ${ }^{208,209}$. Despite the differences in the underlying mechanisms, it is possible that there are similarities between amyloid fibril formation and fibronectin fibrillogenesis.

\section{$\underline{\text { Generation of fibronectin fibers in cell-free systems }}$}

Initially, fibronectin was considered perhaps the only protein of the extracellular matrix unable to undergo fibrillogenesis in the absence of cells ${ }^{210}$. However, as already discussed, many different chemical agents, such as heparin ${ }^{154}$, polyamines ${ }^{211}$, guanidinium hydrochloride ${ }^{186}$ and anastellin 196 could induce the formation of fibrillar fibronectin structures in vitro. In some of these cases, as for example in the presence of anastellin, fiber formation proceeds through module unfolding and $\beta$ strand swapping ${ }^{194}$. Additionally, mechanical forces or adsorption on surfaces of appropriate 
1 chemistry can lead to the generation of fibronectin fibrillar networks, as summarized in Figure 3A.

2 These observations, together with our current understanding of how integrins pull at fibronectin 3 molecules accumulated on the cell surface and expose self-association sites in order to drive 4 fibrillogenesis, lead to the conclusion that chemical or mechanical stimuli able to partially unfold 5 fibronectin and expose self-association sites may lead to fibronectin multimerization and fiber 6 formation. Certain fibril features are intimately linked with the production method; however, several 7 of these 'artificially' produced fibronectin fibers share important aspects of geometry and molecular 8 architecture with cell-derived fibronectin fibers, and they support cell adhesion and migration. Thus, 9 they can be used both as systems for the study of fibronectin fibrillogenesis, and as basic materials 10 for the generation of tissue engineering scaffolds. Here, we will discuss some of these cell-free 11 systems of fibronectin fiber formation and their potential applications.

I2 The medicinal use of superfibronectin, the anastellin-induced fibrillar fibronectin matrix, has 13 already been discussed in the previous section. A completely different way to produce fibrillar 14 fibronectin networks is through adsorption on surfaces of well-defined chemistry, a process termed 15 material-driven assembly ${ }^{212}$. Changes in the substrate chemistry as small as one carbon atom can 16 abolish their ability to support fibril assembly: fibronectin spontaneously organizes into a fibrillar 17 network on poly(ethyl acrylate) (PEA), whereas it remains globular on poly(methyl acrylate) (PMA). 18 Interestingly, material driven-assembly on PEA is blocked by the addition of the $\mathrm{I}_{5}-\mathrm{I}_{9} \mathrm{~N}$-terminal 19 fragment of fibronectin, suggesting that it relies on similar self-association sites as cell-derived 20 fibronectin matrices. Moreover, the fibronectin network developed on PEA supports the binding of 21 growth factors on the Hep2 domain and enhances their activity. Implants coated with PEA, 22 fibronectin and BMP-2 showed superior healing capacity in an in vivo bone repair model, and 23 required much less amount of BMP-2 than traditional growth factor delivery systems ${ }^{213}$. Similarly, 24 the ability of VEGF to induce vascularization was enhanced in PEA implants coated with 25 fibronectin ${ }^{214}$. In both cases, the results depended on the ability of fibronectin fibrillar networks 
1 grown on PEA to mediate simultaneous binding of integrins and soluble growth factors in a manner

2 that allows their synergistic action.

3 In a related process, termed surface-initiated fibronectin assembly or patterning on topography

4 (PoT) 183,215, fibronectin is adsorbed onto a topographically patterned hydrophobic 5 polydimethylsiloxane (PDMS) surface, which partially unfolds the molecule, exposing self6 association sites. The resulting fibronectin layer is then transferred into a thermally responsive 7 poly(N-isopropylacrylamide) (PIPAAm) surface through microcontact printing. During the final step, 8 PIPAAm is dissolved by adjusting the temperature, releasing the fibronectin layer, which has adopted 9 the pattern imprinted on the PDMS surface. Although this is not a spontaneous fibrillogenesis 10 process, it allows the formation of free-standing fibronectin nanotextiles, as complex as the pattern 11 printed onto the PDMS surface, and it can be applied to many other extracellular matrix proteins ${ }^{215}$. 12 Fibronectin nanofabrics have been used to investigate the effects of extracellular matrix geometry 13 on cell behavior ${ }^{216}$. Cells can even be cultured on the nanostructures before the thermally triggered 14 PIPAAm dissolution, leading to their encapsulation in the resulting nanofabric through a shrink15 wrapping process, without affecting their viability ${ }^{217}$. Cell encapsulation in such nano-scaffolds can 16 be used for cell delivery applications.

17 Another major factor leading to the formation of fibronectin fibers, also employed by cells, is the 18 application of mechanical forces. Mats composed of oriented fibers can be formed upon the 19 application of shear forces on concentrated fibronectin solutions ${ }^{180,218}$, and the process can be scaled20 up by wet extrusion in an acidic coagulation bath to produce materials that can be used as surgical 21 grafts ${ }^{219}$. Freeze-dried and rehydrated fibronectin mats have been successfully used in vivo to repair 22 injuries in the peripheral and central nervous system ${ }^{220-224}$. One of the essential elements in these 23 grafts is their oriented fibers, which can act as conduits for cell migration, facilitating tissue 24 regeneration and reducing scarring. This is especially important for the repair of tissues such as 25 nerve, tendon and blood vessels ${ }^{225}$. 
Early studies showed that fibers of well-controlled orientation could be produced by pulling with

2

a rod from a fibronectin solution ${ }^{180,218}$. Studies from one of the authors have shown that in this model system of fibronectin fibrillogenesis, fibers are formed by pulling the fibronectin monolayer that has formed at the air-liquid interface of a droplet (Figure 4) ${ }^{181}$. Fibronectin is known to form stable, insoluble monolayers at air-liquid interfaces 226,227 . Once the surface tension is overcome by the pulling force, the fibronectin monolayer at the interface undergoes a sheet-to-fiber transition. The length of the newly formed fiber increases by the continuous transfer of material from the droplet surface. Sufficiently fast fibronectin adsorption from the droplet solution to the interface refurbishes the material loss, and such fibers can reach lengths up to the cm range ${ }^{181}$. The forces required for the sheet-to-fiber transition are in the $\mathrm{mN}$ range ${ }^{228}$. A related phenomenon is the drawing of lipid tubules from phospholipid vesicles 229 . However, the lipid tubules retract immediately if they are not connected to a vesicle at both ends ${ }^{230}$, whereas the pulled fibronectin fibers remain stable even after they are cut from the fibronectin droplet. This indicates that the transition is irreversible, and the resulting fiber forms a stable structure. It is likely that additionally to the sheet-to-fiber transition, transformations within the fibronectin monolayer, possibly through shear-induced self-association of fibronectin molecules, further stabilize the resulting fiber. As the pulling continues, the sheet buckles at several points and eventually collapses into lamellar structures that curve away from the centripetal direction and form topologically segregated spiral segments extending throughout the length of the fiber. It should be noted that other proteins with the ability to undergo fibrillogenesis and to form insoluble monolayers at the air-water interface, such as BSA, laminin and collagen I, did form fibers by pulling at the interface, suggesting that specific properties of the fibronectin molecules are necessary for the sheet-to-fiber transition to occur ${ }^{181}$. Force-induced fiber formation from a fibronectin monolayer forming at the air-water interface has also been reported in a different setting, using an array of micropillars, which upon wetting, bend and pull on a fibronectin solution suspended between them ${ }^{182}$. In this study, a network of nanofibrils was formed, suspended between the micropillars. 
A

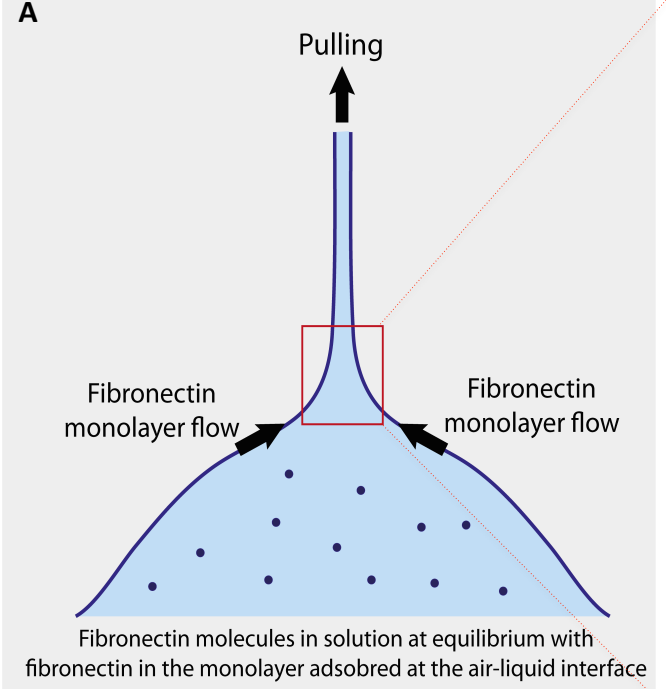

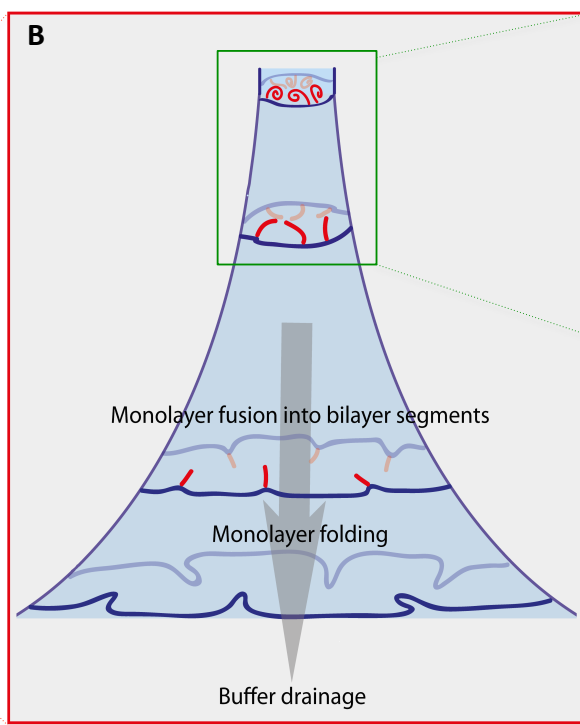

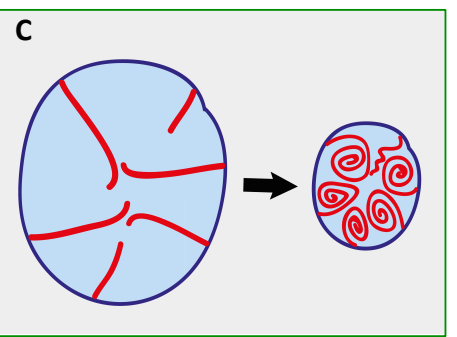

D

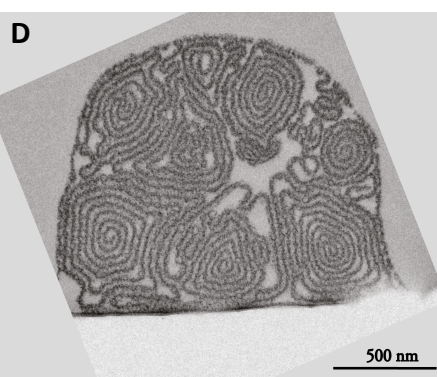

2 Figure 4. Assembly of fibronectin fibers by pulling at the air-water interface. A schematic representation of the irreversible sheet-to-fiber phase transition. Fibronectin adsorbs at the air-water interface forming an insoluble monolayer (A). The tension of pulling and the concomitant buffer drainage induces inward folds in the fibronectin monolayer, which collapse into bilayer folds (B). The increasing space confinement during fiber growth eventually leads to the spiraling of the bilayer folds, generating topologically segregated spiral domains form, extending throughout the length of the fiber (C). Such domains are clearly visible in a transmission electron microscopy image of a fiber cross-section (D) ${ }^{181}$

9 (Reprinted from Biomaterials, 36, Maria Mitsi, Stephan Handschin, Isabel Gerber, Ruth Schwartländer, Enrico Klotzsch, Roger Wepf, Viola Vogel, The ultrastructure of fibronectin fibers pulled from a protein monolayer at the air-liquid interface and the mechanism of the sheet-to-fiber transition, 66-79, 2015, with permission from Elsevier).

additional analogy can be drawn with amyloid fibrils, again, which have been shown to form at the airwater interface by lateral aggregation ${ }^{231}$.

Such manually pulled fibronectin fibers from the air-water interface bear conformational similarities with cell-derived fibronectin fibers, as has been assessed by Fluorescence-Energy Transfer (FRET)-based observations ${ }^{232}$. Moreover, oriented fibronectin fibers of similar dimensions have been observed to colocalize with growing blood vessels in the embryo ${ }^{233}$. Accordingly, studies 
1 from one of the authors have used such fibers to develop a model system to study the interplay

2 between fibronectin and growth factors during the early steps of neovascularization ${ }^{233}$. However,

3 they are not free-standing, and their production cannot easily be scaled up, which makes them more

4 suitable for research and diagnostic assays rather than tissue engineering and therapeutic

5 applications.

6

$7 \quad$ Conclusions and Future Perspectives

8 Decades of intensive research have produced a great number of pieces for the puzzle of fibronectin

9 structure. The picture that has emerged shows a complex structure-function relationship. A

10 hierarchically modular architecture with a large number of self-association sites allows fibronectin

11 to adopt many different conformations, depending on the constantly changing biomechanical

12 properties of the cellular microenvironment. Each conformation may be associated with a set of

13 different binding sites for adhesive receptors and signaling molecules, and therefore, with a different

14 functionality. At the same time, distinct conformations may keep fibronectin in solution or trigger its

I5 fibrillogenesis. Fibrillar fibronectin is also amenable to conformational changes, contributing to the

16 dynamic character of the extracellular matrix. Binding sites may be formed or destroyed depending

17 on the tension applied to the matrix or the presence of structural catalysts, such as heparin. Thus, the

18 conformational flexibility of fibronectin grants it the ability to integrate signals, regulate their

19 presentation to the cells and to some extent, control the cell response. Our knowledge of the

20 underlying mechanisms is fragmented, focusing on single pathways and individual binding events.

$21 \quad$ Future research will help us to understand better how the different mechanisms work together, and

22 build a more comprehensive picture of the structure-function relationship.

\section{$24 \quad$ FIGURE LEGENDS}

25 Figure 1. The multimodular architecture of fibronectin. Schematic representation of modules type I 26 (purple), type II (green) and type III (red) constituting one chain of fibronectin. The alternatively spliced 
1 type III modules EDA and EDB, as well as the alternatively spliced region V are shown in a lighter color.

2 The disulfide bridges linking the two chains at their C-termini in an antiparallel fashion are also shown.

3 Several modules are forming functional domains displaying distinct binding affinities, and they can be

4 released as stable fragments by proteolysis. The major proteolytic sites and the respective proteases are

5 shown, together with the molecular weights of the resulting fragments (bottom), and some of their binding

6 affinities (top).

8 Figure 2. The catalytic mechanism of heparin altering fibronectin conformation. Interactions between

9 heparin (wavy line) and fibronectin induce a conformational change from a compact (gray) to an extended

10 (red) configuration, which reduces the affinity for heparin, allowing for its dissociation, diffusion and

I1 binding to neighboring fibronectin molecules. In this way, substoichiometric amounts of heparin can alter

12 the conformation of the entire fibronectin matrix, acting as a structural catalyst. Three catalytic cycles are

13 shown. One of the functional consequences of the heparin-catalyzed conformational change on fibronectin

14 is the exposure of cryptic growth factor binding sites on the Hep2 $\left(\mathrm{III}_{12}-\mathrm{III}_{14}\right)$ domain of fibronectin ${ }^{66}$.

16 Figure 3. Fibronectin fibrillogenesis and multimerization. (A) The ability of fibronectin to undergo

17 fibrillogenesis is an inherent property of the molecule. During extracellular matrix assembly, cells drive

18 fibronectin fibrillogenesis by using a combination of biochemical fibronectin-integrin interactions and

19 traction forces ${ }^{44}$. However, the formation of fibrillar structures and networks can be promoted artificially,

20 by chemical or physical forces that can expose self-association sites on fibronectin molecules. Several of 21 such factors, including shear forces ${ }^{45-47}$, surface adsorption ${ }^{48,49}$, chemical denaturation ${ }^{51}$, and interactions 22 with polyanions ${ }^{209}$, heparin ${ }^{182}$ and peptides such as anastellin ${ }^{79}$ are listed, along with the fibrillar material 23 produced in each case. (B) High-resolution NMR structure of a complex between anastellin (blue) and 24 module $\mathrm{III}_{1}$ of fibronectin (red), demonstrating the $\beta$-swapping mechanism: two $\beta$-strands from $\mathrm{III}_{1}$ are 25 unfolded and substituted with the two $\beta$-strands from anastellin. (C) Schematic representation of a 
1 hypothetical $\beta$-swapping mechanism that could support fibronectin fibrillogenesis. Type III modules from

2 different fibronectin molecules (each shown in a different color) interact with each other through a $\beta$ -

3 swapping mechanism, with each module offering one $\beta$-strand. The connection of this $\beta$-strand with the

4 rest of the module is shown as a dashed line, drawn intentionally larger for clarity.

6 Figure 4. Assembly of fibronectin fibers by pulling at the air-water interface. A schematic representation 7 of the irreversible sheet-to-fiber phase transition. Fibronectin adsorbs at the air-water interface forming an

8 insoluble monolayer (A). The tension of pulling and the concomitant buffer drainage induces inward folds 9 in the fibronectin monolayer, which collapse into bilayer folds (B). The increasing space confinement 10 during fiber growth eventually leads to the spiraling of the bilayer folds, generating topologically I1 segregated spiral domains form, extending throughout the length of the fiber (C). Such domains are clearly 12 visible in a transmission electron microscopy image of a fiber cross-section (D) ${ }^{181}$. (Reprinted from 13 Biomaterials, 36, Maria Mitsi, Stephan Handschin, Isabel Gerber, Ruth Schwartländer, Enrico Klotzsch, 14 Roger Wepf, Viola Vogel, The ultrastructure of fibronectin fibers pulled from a protein monolayer at the 15 air-liquid interface and the mechanism of the sheet-to-fiber transition, 66-79, 2015, with permission from 16 Elsevier).

18 AUTHOR INFORMATION

19 Co-corresponding authors: *Raffaele Mezzenga, *Maria Mitsi

20 Laboratory of Food and Soft Materials,

$21 \quad$ ETH Zurich, Switzerland

22 $\quad$ raffaele.mezzenga@hest.ethz.ch

23 maria.mitsi@hest.ethz.ch 
2 (1) Zollinger, A. J.; Smith, M. L. Fibronectin, the Extracellular Glue. Matrix Biol. 2016, http://dx.doi.org/10.1016/ j.matbio.2016.07.011.

4 (2) Oh, E.; Pierschbacher, M.; Ruoslahti, E. Deposition of Plasma Fibronectin in Tissues. Proc. Natl. Acad.Sci.U.S.A. 1981, 78 (5), 3218-3221.

6 (3) Mosher, D. F. Physiology of Fibronectin. Annu Rev Med 1984, 35, 561-575.

7 (4) Cho, J.; Mosher, D. F. Role of Fibronectin Assembly in Platelet Thrombus Formation. J. Thromb. Haemost. 2006, 4, 1461-1469.

9 (5) Czop, J. K. Phagocytosis of Particulate Activators of the Alternative Complement Pathway: Effects of Fibronectin. Adv Immunol 1986, 38 (1965), 361-398.

11 (6) Grinnell, F. Fibronectin and Wound Healing. J Cell Biochem 1984, 26 (2), 107-116.

12 (7) Astrof, S.; Hynes, R. O. Fibronectins in Vascular Morphogenesis. Angiogenesis 2009, 12 (2), 165175.

14 (8) Davidson, L. A.; Dzamba, B. J.; Keller, R.; DeSimone, D. W. Live Imaging of Cell Protrusive

(9) George, E. L.; Georges-Labouesse, E. N.; Patel-King, R. S.; Rayburn, H.; Hynes, R. O. Defects in Activity, and Extracellular Matrix Assembly and Remodeling during Morphogenesis in the Frog, Xenopus Laevis. Dev. Dyn. 2008, 273 (2), 2684-2692. 
(12) Stoppacciaro, A.; Pietrucci, A.; Fofi, C.; Raffa, S.; Torrisi, M. R.; Men, P. Fibronectin Glomerulopathy : An Uncommon Cause of Nephrotic Syndrome in Systemic Lupus Erythematosus. NDT Plus 2008, No. 4, 225-227.

(13) Kawahara, E.; Shiroo, M.; Nakanishi, I.; Migita, S. The Role of Fibronectin in the Development of Experimental Amyloidosis. Evidence of Immunohistochemical Codistribution and Binding Property with Serum Amyloid Protein A. Am J Pathol 1989, 134 (6), 1305-1314.

(14) Akiyama, S. K.; Olden, K.; Yamada, K. M. Fibronectin and Integrins in Invasion and Metastasis. Cancer Metastasis Rev. 1995, 14 (3), 173-189.

(15) Morrison, P. R.; Edsall, J. T.; Miller, S. G. Preparation and Properties of Serum and Plasma Proteins. XVIII. The Separation of Purified Fibrinogen from Fraction I of Human Plasma. J. Am. Chem. Soc. 1948, 70 (9), 3103-3108.

(16) Mosesson, M. W.; Umfleet, R. A. The Cold-Insoluble Globulin of Human Plasma. J. Biol. Chem. 1970, 245 (21), 5728-5736.

(17) Molnar, J.; McLain, S.; Allen, C.; Laga, H.; Gara, A.; Gelder, F. The Role of an alpha2Macroglobulin of Rat Serum in the Phagocytosis of Colloidal Particles. Biochim. Biophys. Acta $\mathbf{1 9 7 7 , ~ 4 9 3 , ~ 3 7 - 5 4 . ~}$

(18) Wartiovaara, J.; Linder, E.; Ruoslahti, E.; Vaheri, A. Distribution of Fibroblast Surface Antigen: Association with Fibrillar Structures of Normal Cells and Loss Upon Viral Transformation. J. Exp. Med. 1974, 140, 1522-1533.

(19) Chen, L. B.; Murray, A.; Segal, R. A.; Bushnell, A.; Walsh, M. L. Studies on Intercellular LETS Glycoprotein Matrices. Cell 1978, 14 (2), 377-391.

(20) Vaheri, A.; Mosher, D. F. High Molecular Weight, Cell Surface-Associated Glycoprotein 
(21) McDonagh, J. Plasma Fibronectin: Structure and Function; 1985.

(22) Kar, L.; Lai, C. S.; Wolff, C. E.; Nettesheim, D.; Sherman, S.; Johnson, M. E. H-1 NMR-Based Determination of the 3-Dimensional Structure of the Human Plasma Fibronectin Fragment Containing Inter- Chain Disulfide Bonds. J. Biol. Chem. 1993, 268 (12), 8580-8589.

(23) Johansson, S.; Svineng, G.; Wennerberg, K.; Armulik, A.; Lohikangas, L. Fibronectin-Integrin Interactions. Front. Biosci. 1997, 2 (11), d126-46.

(24) Balian, G.; Click, E. M.; Bornstein, P. Location of a Collagen-Binding Domain in Fibronectin. J Biol Chem 1980, 255 (8), 3234-3236.

(25) Yamada, K. M.; Kennedy, D. W.; Kimata, K.; Pratt, R. M. Characterization of Fibronectin Interactions with Glycosaminoglycans and Identification of Active Proteolytic Fragments. J Biol Chem 1980, 255 (13), 6055-6063.

(26) Corbett, S. A.; Schwarzbauer, J. E. Fibronectin-Fibrin Cross-Linking: A Regulator of Cell Behavior. Trends Cardiovasc. Med. 1998, 8 (8), 357-362.

(27) Calaycay, J.; Pande, H.; Lee, T.; Borsi, L.; Siri, A.; Shively, J. E.; Zardi, L. Primary Structure of a DNA- and Heparin-Binding Domain (Domain III) in Human Plasma Fibronectin. J Biol Chem 1985, 260 (22), 12136-12141.

(28) Sekiguchi, K.; Hakomori, S. Functional Domain Structure of Fibronectin. Proc. Natl. Acad. Sci. 1980, $77(5), 2661-2665$.

(29) Khan, M. Y.; Medow, M. S.; Newman, S. A. Unfolding Transitions of Fibronectin and Its Domains - Stabilization and Structural Alteration of the N-Terminal Domain by Heparin. Biochem. J. 1990, $270(1), 33-38$.

(30) de Carreira, P. F.; Castellino, F. J. The Thermotropic Properties of Human Plasma Fibronectin. Arch. 
(31) Ingham, K. C.; Brew, S. A.; Broekelmann, T. J.; McDonald, J. A. Thermal Stability of Human Plasma Fibronectin and Its Constituent Domains. J. Biol. Chem. 1984, 259 (19), 11901-11907.

(32) Tatunashvili, L. V.; Filimonov, V. V.; Privalov, P. L.; Metsis, M. L.; Koteliansky, V. E.; Ingham, K. C.; Medved, L. V. Co-Operative Domains in Fibronectin. J. Mol. Biol. 1990, 211 (1), 161-169.

(33) Pankov, R.; Yamada, K. M. Fibronectin at a Glance. J Cell Sci 2002, 115 (Pt 20), 3861-3863.

(34) Schwarzbauer, J. E. Alternative Splicing of Fibronectin: Three Variants, Three Functions. Bioessays 1991, 13 (10), 527-533.

(35) Litvinovich, S. V; Strickland, D. K.; Ingham, K. C. Domain Structure and Interactions Modules in the Gelatin-Binding of the Type I and Type II Region of Fibronectin Folded. J. Mol. Biol. 1991, 217, 563-575.

(36) Litvinovich, S. V; Ingham, K. C. Interactions between Type III Domains in the 110 kDa CellBinding Fragment of Fibronectin. J Mol Biol 1995, 248 (3), 611-626.

(37) Novokhatny, V.; Schwarz, F.; Atha, D.; Ingham, K. Domain Structure and Domain-Domain Interactions in the Carboxy-Terminal Heparin Binding Region of Fibronectin. J Mol Biol 1992, 227 (4), 1182-1191.

(38) Rudiño-Piñera, E.; Ravelli, R. B. G.; Sheldrick, G. M.; Nanao, M. H.; Korostelev, V. V; Werner, J. M.; Schwarz-linek, U.; Potts, J. R.; Garman, E. F. The Solution and Crystal Structures of a Module Pair from the Staphylococcus Aureus -Binding Site of Human Fibronectin - A Tale with a Twist. J. Mol. Biol. 2007, 368, 833-844.

(39) Williams, M. J.; Phan, I.; Harvey, T. S.; Rostagno, A.; Gold, L. I.; Campbell, I. D. Solution Structure of a Pair of Fibronectin Type 1 Modules with Fibrin Binding Activity. J Mol Biol 1994, 235 (4), 1302-1311. 
(40) Smith, S. P.; Hashimoto, Y.; Pickford, A. R.; Campbell, I. D.; Werner, M. Interface Characterization of the Type II Module Pair from Fibronectin. Biochemistry 2000, 39, 8374-8381.

(41) Bocquier, A. A.; Potts, J. R.; Pickford, A. R.; Campbell, I. D. Solution Structure of a Pair of Modules from the Gelatin-Binding Domain of Fibronectin. Structure 1999, 7 (12), 1451-1460.

(42) Hashimoto, Y.; Smith, S. P.; Pickford, A. R.; Bocquier, A. A.; Campbell, I. D.; Werner, J. M. The Relative Orientation of the Fibronectin (6)F1(1)F2 Module Pair: A N-15 NMR Relaxation Study. $J$. Biomol. Nmr 2000, 17 (3), 203-214.

(43) Johnson, K. J.; Sage, H.; Briscoe, G.; Erickson, H. P. The Compact Conformation of Fibronectin Is Determined by Intramolecular Ionic Interactions. J. Biol. Chem. 1999, 274 (22), 15473-15479.

(44) Pickford, A. R.; Smith, S. P.; Staunton, D.; Boyd, J.; Campbell, I. D. The Hairpin Structure of the (6)F1(1)F2(2)F2 Fragment from Human Fibronectin Enhances Gelatin Binding. Embo J 2001, 20 (7), 1519-1529.

(45) Erat, M. C.; Schwarz-Linek, U.; Pickford, A. R.; Farndale, R. W.; Campbell, I. D.; Vakonakis, I. Implications for Collagen Binding from the Crystallographic Structure of Fibronectin 6FnI12FnII7FnI. J. Biol. Chem. 2010, 285 (44), 33764-33770.

(46) Graille, M.; Pagano, M.; Rose, T.; Ravaux, M. R.; Van Tilbeurgh, H. Zinc Induces Structural Reorganization of Gelatin Binding Domain from Human Fibronectin and Affects Collagen Binding. Structure 2010, 18, 710-718.

(47) Erat, C.; Slatter, D. A.; Lowe, E. D.; Millard, C. J.; Farndale, R. W.; Campbell, I. D. Identification and Structural Analysis of Type I Collagen Sites in Complex with Fibronectin Fragments. Proc. Natl. Acad.Sci. 2009, 106 (11), 4195-4200.

(48) Williams, E. C.; Janmey, P. A.; Ferry, J. D.; Mosher, D. F. Conformational States of Fibronectin. Effects of pH, Ionic Strength, and Collagen Binding. J Biol Chem 1982, 257 (24), 14973-14978. 
1 (49) Erickson, H. P.; Carrell, N. A. Fibronectin in Extended and Compact Conformations. Electron Microscopy and Sedimentation Analysis. J Biol Chem 1983, 258 (23), 14539-14544.

(50) Bergkvist, M.; Carlsson, J.; Oscarsson, S. Surface-Dependent Conformations of Human Plasma Fibronectin Adsorbed to Silica, Mica, and Hydrophobic Surfaces, Studied with Use of Atomic Force Microscopy. J Biomed Mater Res 2003, 64A (2), 349-356.

(51) Vogel, V. Mechanotransduction Involving Multimodular Proteins: Converting Force into Biochemical Signals. Annu Rev Biophys Biomol Struct 2006, 35, 459-488.

(52) Maurer, L. M.; Ma, W.; Mosher, D. F. Dynamic Structure of Plasma Fibronectin. Crit. Rev. Biochem. Mol.Biol. 2016, 51 (4), 231-227.

(53) Rocco, M.; Infusini, E.; Daga, M. G.; Gogioso, L.; Cuniberti, C. Models of Fibronectin. Embo J. 1987, 6 (8), 2343-2349.

(54) Iozzo, R. V. Matrix Proteoglycans: From Molecular Design to Cellular Function. Annu Rev Biochem $1998,67,609-652$.

(55) Lindahl, U. "Heparin" - from Anticoagulant Drug into the New Biology. Glycoconj J 2000, 17 (79), 597-605.

(56) Metcalfe, D. D.; Baram, D.; Mekori, Y. A. Mast Cells. Physiol. Rev. 1997, 77 (4), 1033-1079.

(57) Mulloy, B.; Forster, M. J. Conformation and Dynamics of Heparin and Heparan Sulfate. Glycobiology 2000, 10 (11), 1147-1156.

(58) Richter, H.; Seidl, M.; Hörmann, H. Location of Heparin-Binding Sites of Fibronectin. Detection of a Hitherto Unrecognied Transamidase. Hoppe Seylers Z Physiol Chem 1981, 362, 399-408.

(59) Gold, L. I.; Frangione, B.; Pearlstein, E. Biochemical and Immunological Characterization of Three Binding Sites on Human Plasma Fibronectin with Different Affinities for Heparin. Biochemistry 1983, 22 (17), 4113-4119. 
1 (60) Benecky, M. J.; Kolvenbach, C. G.; Amrani, D. L.; Mosesson, M. W. Evidence That Binding to the Fibronectin and Heparin. Biochemistry 1988, 27 (19), 7565-7571.

(61) Hayashi, M.; Yamada, K. M. Divalent Cation Modulation of Fibronectin Binding to Heparin and to DNA. J. Biol. Chem. 1982, 257 (9), 5263-5267.

(62) Ingham, K. C.; Brew, S. A.; Athat, D. H. Interaction of Heparin with Fibronectin and Isolated Fibronectin Domains. Biochem. J. 1990, 272, 605-611.

(63) Kang, W.; Park, S.; Jang, J. H. Kinetic and Functional Analysis of the Heparin-Binding Domain of Fibronectin. Biotechnol. Lett. 2008, 30 (1), 55-59.

(64) Lin, H.; Lal, R.; Clegg, D. O. Imaging and Mapping Heparin-Binding Sites on Single Fibronectin Molecules with Atomic Force Microscopy. Biochemistry 2000, 39 (12), 3192-3196.

(65) Mitchell, G.; Lamontagne, C. A.; Lebel, R.; Grandbois, M.; Malouin, F. Single-Molecule Dynamic Force Spectroscopy of the Fibronectin-Heparin Interaction. Biochem. Biophys. Res. Commun. 2007, $364(3), 595-600$.

(66) Mitsi, M.; Forsten-Williams, K.; Gopalakrishnan, M.; Nugent, M. A. A Catalytic Role of Heparin within the Extracellular Matrix. J Biol Chem 2008, 283 (50), 34796-34807.

(67) Makabe, T.; Saiki, I.; Murata, J.; Ohdate, Y.; Kawase, Y.; Taguchi, Y.; Shimojo, T.; Kimuzuka, F.; Kato, I.; Azuma, I. Modulation of Haptotactic Migration of Metastatic Melanoma Cells by the Interaction between Heparin and Heparin-Binding Domain of Fibronectin. J. Biol. Chem. 1990, 265 (24), 14270-14276.

(68) Ingham, K. C.; Brew, S. A.; Migliorini, M. M.; Busby, T. F. Binding of Heparin by Type III Domains and Peptides from the Carboxy Terminal Hep-2 Region of Fibronectin. Biochemistry 1993, 32 (46), $12548-12553$. 
(69) Barkalow, F. J. B.; Schwarzbauer, J. E. Localization of the Major Heparin-Binding Site in Fibronectin. J. Biol. Chem. 1991, 266 (12), 7812-7818.

(70) Ingham, K. C.; Brew, S. A.; Migliorini, M. An Unusual Heparin-Binding Peptide from the CarboxyTerminal Hep-2 Region of Fibronectin. Arch. Biochem. Biophys. 1994, 314 (2), 242-246.

(71) Mohri, H.; Katoh, K.; Motomura, S.; Okubo, T. Novel Synthetic Peptides from the C-Terminal Heparin Binding Domain of Fibronectin with Heparin Binding Activity. Peptides 1996, 17 (6), $1079-1081$.

(72) Busby, T. F.; Argraves, W. S.; Brew, S. A.; Pechik, I.; Gilliland, G. L.; Ingham, K. C. Heparin Binding by Fibronectin Module III-13 Involves Six Discontinuous Basic Residues Brought Together to Form a Cationic Cradle. Journal of Biological Chemistry. 1995, 270 (31), 18558-18562.

(73) Ogamo, A.; Nagai, A.; Nagasawa, K. Binding of Heparin Fractions and Other Polysulfated Polysaccharides to Plasma Fibronectin: Effects of Molecular Size and Degree of Sulfation of Polysaccharides. BBA - Gen. Subj. 1985, 841 (1), 30-41.

(74) Walker, A.; Gallagher, J. T. Structural Domains of Heparan Sulphate for Specific Recognition of the C-Terminal Heparin-Binding Domain of Human Plasma Fibronectin (HEPII). Biochem J 1996, 317 (Pt 3), 871-877.

(75) Lyon, M.; Rushton, G.; Askari, J. A.; Humphries, M. J.; Gallagher, J. T. Elucidation of the Structural Features of Heparan Sulfate Important for Interaction with the Hep-2 Domain of Fibronectin. J Biol Chem 2000, 275 (7), 4599-4606.

(76) Mahalingam, Y.; Gallagher, J. T.; Couchman, J. R. Cellular Adhesion Responses to the HeparinBinding (HepII) Domain of Fibronectin Require Heparan Sulfate with Specific Properties. J Biol Chem 2007, 282 (5), 3221-3230.

(77) Mitsi, M.; Hong, Z.; Costello, C. E.; Nugent, M. A. Heparin-Mediated Conformational Changes in Fibronectin Expose Vascular Endothelial Growth Factor Binding Sites. Biochemistry 2006, 45 (34), 
(78) Hubbard, B.; Buczek-Thomas, J. A.; Nugent, M. A.; Smith, M. L. Heparin-Dependent Regulation of Fibronectin Matrix Conformation. Matrix Biol. 2014, 34, 124-131.

(79) Niedzwiadek, W. E.; O’Bryan, G. T.; Blumenstock, F. A.; Saba, T. M.; Andersen, T. T. A Calorimetric Analysis of Human Plasma Fibronectin: Effects of Heparin Binding on Domain Structure. Biochemistry 1988, 27 (18), 7116-7124.

(80) Smith, E. M.; Mitsi, M.; Nugent, M. A.; Symes, K. PDGF-A Interactions with Fibronectin Reveal a Critical Role for Heparan Sulfate in Directed Cell Migration during Xenopus Gastrulation. Proc. Natl. Acad. Sci. U. S. A. 2009, 106 (51), 21683-21688.

(81) Martino, M. M.; Hubbell, J. A. The 12th-14th Type III Repeats of Fibronectin Function as a Highly Promiscuous Growth Factor-Binding Domain. Faseb J 2010, 24 (12), 4711-4721.

(82) Jones, J. I.; Gockerman, A.; Busby, W. H. J.; Camacho-Hubner, C.; Clemmons, D. R. Extracellular Matrix Contains Insulin-like Growth Factor Binding Protein-5: Potentiation of the Effects of IGF-I. J. Cell Biol. 1993, 121 (3), 679-687.

(83) Gui, Y.; Murphy, L. J. Insulin-like Growth Factor (IGF)-Binding Protein-3 (IGFBP-3) Binds to Fibronectin (FN): Demonstration of IGF-I/IGFBP-3/FN Ternary Complexes in Human Plasma. $J$. Clin. Endocrinol. Metab. 2001, 86 (5), 2104-2110.

(84) Rahman, S.; Patel, Y.; Murray, J.; Patel, K. V; Sumathipala, R.; Sobel, M.; Wijelath, E. S. Novel Hepatocyte Growth Factor (HGF) Binding Domains on Fibronectin and Vitronectin Coordinate a Distinct and Amplified Met-Integrin Induced Signalling Pathway in Endothelial Cells. BMC Cell Biol 2005, 6 (1), 8 .

(85) Pi, L.; Ding, X.; Jorgensen, M.; Pan, J. J.; Oh, S. H.; Pintilie, D.; Brown, A.; Song, W. Y.; Petersen, B. E. Connective Tissue Growth Factor with a Novel Fibronectin Binding Site Promotes Cell Adhesion and Migration during Rat Oval Cell Activation. Hepatology 2008, 47 (3), 996-1004. 
(86) Wijelath, E. S.; Rahman, S.; Namekata, M.; Murray, J.; Nishimura, T.; Mostafavi-Pour, Z.; Patel, Y.; Suda, Y.; Humphries, M. J.; Sobel, M. Heparin-II Domain of Fibronectin Is a Vascular Endothelial Growth Factor-Binding Domain: Enhancement of VEGF Biological Activity by a Singular Growth Factor/matrix Protein Synergism. Circ. Res. 2006, 99 (8), 853-860.

(87) Small, A. R.; Neagu, A.; Amyot, F.; Sackett, D.; Chernomordik, V.; Gandjbakhche, A. Spatial Distribution of VEGF Isoforms and Chemotactic Signals in the Vicinity of a Tumor. $J$ Theor Biol 2008, 252 (4), 593-607.

(88) Ruhrberg, C.; Gerhardt, H.; Golding, M.; Watson, R.; Ioannidou, S.; Fujisawa, H.; Betsholtz, C.; Shima, D. T. Spatially Restricted Patterning Cues Provided by Heparin-Binding VEGF-A Control Blood Vessel Branching Morphogenesis. Genes Dev 2002, 16 (20), 2684-2698.

(89) Chen, T. T.; Luque, A.; Lee, S.; Anderson, S. M.; Segura, T.; Iruela-Arispe, M. L. Anchorage of VEGF to the Extracellular Matrix Conveys Differential Signaling Responses to Endothelial Cells. $J$. Cell Biol. 2010, 188 (4), 595-609.

(90) Anderson, S. M.; Chen, T. T.; Iruela-Arispe, M. L.; Segura, T. The Phosphorylation of Vascular Endothelial Growth Factor Receptor-2 (VEGFR-2) by Engineered Surfaces with Electrostatically or Covalently Immobilized VEGF. Biomaterials 2009, 30 (27), 4618-4628.

(91) Lin, F.; Ren, X. D.; Pan, Z.; Macri, L.; Zong, W. X.; Tonnesen, M. G.; Rafailovich, M.; Bar-Sagi, D.; Clark, R. A. Fibronectin Growth Factor-Binding Domains Are Required for Fibroblast Survival. J Invest Dermatol 2011, 131 (1), 84-98.

(92) Lin, F.; Zhu, J.; Tonnesen, M. G.; Taira, B. R.; McClain, S. A.; Singer, A. J.; Clark, R. A. F. Fibronectin Peptides That Bind PDGF-BB Enhance Survival of Cells and Tissue under Stress. $J$ Invest Dermatol 2014, 134 (4), 1119-1127.

(93) Sawicka, K. M.; Seeliger, M.; Musaev, T.; Macri, L. K.; Clark, R. A. F. Fibronectin Interaction and Enhancement of Growth Factors : Importance for Wound Healing. Adv. Wound Care 2015, 4 (8), 
(94) Chabria, M.; Hertig, S.; Smith, M. L.; Vogel, V. Stretching Fibronectin Fibres Disrupts Binding of Bacterial Adhesins by Physically Destroying an Epitope. Nat Commun 2010, 1, 135.

(95) Kubow, K. E.; Vukmirovic, R.; Zhe, L.; Klotzsch, E.; Smith, M. L.; Gourdon, D.; Luna, S.; Vogel, V. Mechanical Forces Regulate the Interactions of Fibronectin and Collagen I in Extracellular Matrix. Nat. Commun. 2015, 6, 8026.

(96) Little, W. C.; Schwartlander, R.; Smith, M. L.; Gourdon, D.; Vogel, V. Stretched Extracellular Matrix Proteins Turn Fouling and Are Functionally Rescued by the Chaperones Albumin and Casein. Nano Lett 2009, 9 (12), 4158-4167.

(97) Ortiz Franyuti, D.; Mitsi, M.; Vogel, V. Mechanical Stretching of Fibronectin Fibers Upregulates Binding of Interleukin-7. Nano Lett. 2018, 18 (1), 15-25.

(98) Hynes, R. O. Integrins: Versatility, Modulation, and Signaling in Cell Adhesion. Cell 1992, 69 (1), $11-25$.

(99) Baron, M.; Main, A. L.; Driscoll, P. C.; Mardon, H. J.; Boyd, J.; Campbell, I. D. 1H NMR Assignment and Secondary Structure of the Cell Adhesion Type III Module of Fibronectin. Biochemistry 1992, 31 (7), 2068-2073.

(100) Main, A. L.; Harvey, T. S.; Baron, M.; Boyd, J.; Campbell, I. D. The Three-Dimensional Structure of the Tenth Type III Module of Fibronectin: An Insight into RGD-Mediated Interactions. Cell 1992, $71(4), 671-678$.

(101) Carr, P. A.; Erickson, H. P.; Palmer, A. G. Backbone Dynamics of Homologous Fibronectin Type III Cell Adhesion Domains from Fibronectin and Tenascin. Structure 1997, 5 (7), 949-959.

(102) Dickinson, C. D.; Veerapandian, B.; Dai, X.-P.; Hamlin, R. C.; Xuong, N.; Ruoslahti, E.; Ely, K. R. Crystal Structure of the Tenth Type $\{$ III $\}$ Cell Adhesion Molecule of Human Fibronectin. J. Mol. 
Biol 1994, 236, 1079-1092.

(103) Obara, M.; Kang, M. S.; Yamada, K. M. Site-Directed Mutagenesis of the Cell-Binding Domain of Human Fibronectin: Separable, Synergistic Sites Mediate Adhesive Function. Cell 1988, 53 (4), 649-657.

(104) Aota, S.; Nagai, T.; Olden, K.; Akiyama, S. K.; Yamada, K. M. Fibronectin and Integrins in Cell Adhesion and Migration. Biochem Soc Trans 1991, 19 (4), 830-835.

(105) Nagai, T.; Yamakawa, N.; Aota, S.; Yamada, S. S.; Akiyama, S. K.; Olden, K.; Yamada, K. M. Monoclonal Antibody Characterization of Two Distant Sites Required for Function of the Central Cell-Binding Domain of Fibronectin in Cell Adhesion, Cell Migration, and Matrix Assembly. J. Cell Biol. 1991, 114 (6), 1295-1305.

(106) Bowditch, R. D.; Hariharan, M.; Tominna, E. F.; Smith, J. W.; Yamada, K. M.; Getzoff, E. D.; Ginsberg, M. H. Identification of a Novel Integrin Binding-Site in Fibronectin - Differential Utilization By Beta-3 Integrins. J. Biol. Chem. 1994, 269 (14), 10856-10863.

(107) Aota, S. I.; Nomizu, M.; Yamada, K. M. The Short Amino Acid Sequence Pro-His-Ser-Arg-Asn in Human Fibronectin Enhances Cell-Adhesive Function. J. Biol. Chem. 1994, 269 (40), 24756-24761.

(108) Mould, A. P.; Askari, J. A.; Aota, S.; Yamada, K. M.; Irie, A.; Takada, Y.; Mardon, H. J.; Humphries, M. J. Defining the Topology of Integrin a5b1-Fibronectin Interactions Using Inhibitory Anti-a5 and Anti-b1 Monoclonal Antibodies. J. Biol. Chem. 1997, 272 (28), 17283-17292.

(109) Mould, A. P.; Symonds, E. J. H.; Buckley, P. A.; Grossmann, J. G.; McEwan, P. A.; Barton, S. J.; Askari, J. A.; Craig, S. E.; Bella, J.; Humphries, M. J. Structure of an Integrin-Ligand Complex Deduced from Solution X-Ray Scattering and Site-Directed Mutagenesis. J. Biol. Chem. 2003, 278 (41), 39993-39999.

(110) Adair, B. D.; Xiong, J. P.; Maddock, C.; Goodman, S. L.; Arnaout, M. A.; Yeager, M. ThreeDimensional EM Structure of the Ectodomain of Integrin $\alpha \mathrm{V} \beta 3$ in a Complex with Fibronectin. $J$. 
2 (111) Grant, R. P.; Spitzfaden, C.; Altroff, H.; Campbell, I. D.; Mardon, H. J. Structural Requirements for Biological Activity of the Ninth and Tenth FIII Domains of Human Fibronectin. J. Biol. Chem. 1997, 272 (10), 6159-6166.

(112) Copie, V.; Tomita, Y.; Akiyama, S. K.; Aota, S.; Yamada, K. M.; Venable, R. M.; Pastor, R. W.; Krueger, S.; Torchia, D. A. Solution Structure and Dynamics of Linked Cell Attachment Modules of Mouse Fibronectin Containing the RGD and Synergy Regions: Comparison with the Human Fibronectin Crystal Structure. J Mol Biol 1998, 277 (3), 663-682.

(113) Leahy, D. J.; Aukhil, I.; Erickson, H.P.2.0 A Crystal Structure of a Four-Domain Segment of Human Fibronectin Encompassing the RGD Loop and Synergy Region. Cell 1996, 84 (1), 155-164.

(114) Danen, E. H. J.; Aota, S.; van Kraats, A.; Yamada, K. M.; Dirk, J.; van Muijen, G. N. P.; van Kraats, A. A. Requirement for the Synergy Site for Cell Adhesion to Fibronectin Depends on the Activation State of Integrin $\alpha 5 \beta 1.1995,270(37), 1-8$.

(115) Chen, J.; Maeda, T.; Sekiguchi, K.; Sheppard, D. Distinct Structural Requirements for Interaction of the Integrins alpha5 beta1, Alpha v beta5, and Alpha v beta6 with the Central Cell Binding Domain in Fibronectin. Cell Adhes. Commun. 1996, 4 (4-5), 237-250.

(116) Garcia, A. J.; J, T.; D, B. Two-Stage Activation for alpha5 beta1 Integrin Binding to SurfaceAdsorbed Fibronectin. J. Biol. Chem. 1998, 273 (52), 34710-34715.

(117) Redick, S. D.; Settles, D. L.; Briscoe, G.; Erickson, H. P. Defining Fibronectin' S Cell Adhesion Synergy Site by Site-Directed Mutagenesis. J. Cell Biol. 2000, 149 (2), 521-527.

(118) Altroff, H.; Choulier, L.; Mardon, H. J. Synergistic Activity of the Ninth and Tenth FIII Domains of Human Fibronectin Depends upon Structural Stability. J. Biol. Chem. 2003, 278 (1), 491-497.

(119) Friedland, J. C.; Lee, M. H.; David, B. Mechanically Activated Integrin Switch Controls a5b1 
Function. Science (80-. ). 2009, 323 (5914), 642-644.

(120) Krammer, A.; Craig, D.; Thomas, W. E.; Schulten, K.; Vogel, V. A Structural Model for Force Regulated Integrin Binding to Fibronectin’s RGD-Synergy Site. Matrix Biol. 2002, 21 (2), 139-147.

(121) Singh, P.; Carraher, C.; Schwarzbauer, J. E. Assembly of Fibronectin Extracellular Marix. Annu Rev Cell Dev Biol 2010, 26, 397-419.

(122) Zhong, C.; Chrzanowska-Wodnicka, M.; Brown, J.; Shaub, A.; Belkin, A. M.; Burridge, K. RhoMediated Contractility Exposes a Cryptic Site in Fibronectin and Induces Fibronectin Matrix Assembly. J. Cell Biol. 1998, 141 (2), 539-551.

(123) Burridge, K.; Chrzanowska-Wodnicka, M. Focal Adhesions, Contractility, and Signaling. Annu. Rev. Cell Dev. Biol. 1996, 12 (1), 463-519.

(124) Ali, I. U.; Hynes, R. O. Effects of Cytochalasin B and Colchicine on Attachment of a Major Surface Protein of Fibroblasts. Biochim. Biophys. Acta 1977, 471, 16-24.

(125) Wu, C.; Keivens, V. M.; O’Toole, T. E.; McDonald, J. A.; Ginsberg, M. H. Integrin Activation and Cytoskeletal Interaction Are Essential for the Assemble of a Fibronectin Matrix. Cell 1995, 83(5), $715-724$.

(126) Christopher, R. A.; Kowalczyk, A. P.; McKeown-Longo, P. J. Localization of Fibronectin Matrix Assembly Sites on Fibroblasts and Endothelial Cells. J. Cell Sci.1997, 110 (5), 569-581.

(127) McDonald, J. A.; Quade, B. J.; Broekelmann, T. J.; LaChance, R.; Forsman, K.; Hasegawa, E.; Akiyama, S. Fibronectin's Cell-Adhesive Domain and an Amino-Terminal Matrix Assembly Domain Participate in Its Assembly into Fibroblast Pericellular Matrix. J. Biol. Chem. 1987, 262 (7), 2957-2967.

(128) Roman, J.; LaChance, R.; Broekelmann, T. J.; Kennedy, C. J. R.; Wayner, E. A.; Carter, W. G.; McDonald, J. A. The Fibronectin Receptor Is Organized by Extracellular Matrix Fibronectin: 
Implications for Oncogenic Transformation and for Cell Recognition of Fibronectin Matrices. J. Cell Biol. 1989, 108, 2529-2453.

(129) Fogerty, F. J.; Akiyama, S. K.; Yamada, K. M.; Mosher, D. E. Inhibition of Binding of Fibronectin to Matrix Assembly Sites by Anti-Integrin (Alpha 5 Beta 1) Antibodies. J. Cell Biol. 1990, 111 (2), 699-708.

(130) Wu, C.; Bauer, J. S.; Juliano, R. L.; McDonald, J. A. The Alpha 5 Beta 1 Integrin Fibronectin Receptor, but Not the Alpha 5 Cytoplasmic Domain, Functions in an Early and Essential Step in Fibronectin Matrix Assembly. J Biol Chem 1993, 268 (29), 21883-21888.

(131) Huveneers, S.; Truong, H.; Fassler, R.; Sonnenberg, A.; Danen, E. H. J. Binding of Soluble Fibronectin to Integrin 51 - Link to Focal Adhesion Redistribution and Contractile Shape. J. Cell Sci. 2008, 121 (15), 2452-2462.

(132) Pankov, R.; Cukierman, E.; Katz, B. Z.; Matsumoto, K.; Lin, D. C.; Lin, S.; Hahn, C.; Yamada, K. M. Integrin Dynamics and Matrix Assembly: Tensin-Dependent Translocation of alpha5beta1 Integrins Promotes Early Fibronectin Fibrillogenesis. J. Cell Biol. 2000, 148 (5), 1075-1090.

(133) Lemmon, C. A.; Chen, C. S.; Romer, L. H. Cell Traction Forces Direct Fibronectin Matrix Assembly. Biophys. J. 2009, 96 (2), 729-738.

(134) Mao, Y.; Schwarzbauer, J. E. Fibronectin Fibrillogenesis, a Cell-Mediated Matrix Assembly Process. Matrix Biol. 2005, 24 (6), 389-399.

(135) Schwarzbauer, J. E. Identification of the Fibronectin Sequences Required for Assembly of a Fibrillar Matrix. J Cell Biol 1991, 113 (6), 1463-1473.

(136) Sechler, J. L.; Takada, Y.; Schwarzbauer, J. E. Altered Rate of Fibronectin Matrix Assembly by Deletion of the First Type III Repeats. J Cell Biol 1996, 134 (2), 573-583.

(137) Chernousov, M. A.; Metsis, M. L.; Koteliansky, V. E. Studies of Extracellular Fibronectin Matrix 
Formation with Fluoresceinated Fibronectin and Fibronectin Fragments. FEBS Lett. 1985, 183 (2),

(138) McKeown-Longo, P. J.; Mosher, D. F. Interaction of the 70,000-Mol-Wt Amino-Terminal Fragment of Fibronectin with the Matrix-Assembly Receptor of Fibroblasts. J. Cell Biol. 1985, 100 (2), 364374.

(139) Ichihara-Tanaka, K.; Maeda, T.; Titani, K.; Sekiguchi, K. Matrix Assembly of Recombinant Fibronectin Polypeptide Consisting of Amino-Terminal $70 \mathrm{kDa}$ and Carboxyl-Terminal $37 \mathrm{kDa}$ Regions. FEBS Lett.1992, 299 (2), 155-158.

(140) Ichihara-Tanaka, K.; Titani, K.; Sekiguchi, K. Role of the Carboxyl-Terminal Fib2 Domain in Fibronectin Matrix Assembly. J.Cell Sci.1995, 108, 907-915.

(141) Mckeown-longo, P. J.; Mosher, D. F. Binding of Plasma Fibronectin to Cell Layers of Human Skin Fibroblasts. J. Cell Biol. 1983, 97, 466-472.

(142) Morla, A.; Ruoslahti, E. A Fibronectin Self-Assembly Site Involved in Fibronectin Matrix Assembly: Reconstruction in a Synthetic Peptide. J. Cell Biol. 1992, 118 (2), 421-429.

(143) Chernousov, M. A.; Fogerty, F. J.; Koteliansky, V. E.; Mosher, D. F. Role of the I-9 and III-1 Modules of Fibronectin in Formation of an Extracellular Fibronectin Matrix. J. Biol. Chem. 1991, 266 (17), 10851-10858.

(144) Sechler, J. L.; Rao, H.; Cumiskey, A. M.; Vega-Colón, I.; Smith, M. S.; Murata, T.; Schwarzbauer, J. E. A Novel Fibronectin Binding Site Required for Fibronectin Fibril Growth during Matrix Assembly. J. Cell Biol. 2001, 154 (5), 1081-1088.

(145) Santas, A. J.; Peterson, J. A.; Halbleib, J. L.; Craig, S. E.; Humphries, M. J.; Pesciotta Peters, D. M. Alternative Splicing of the IIICS Domain in Fibronectin Governs the Role of the Heparin II Domain in Fibrillogenesis and Cell Spreading. J. Biol. Chem. 2002, 277 (16), 13650-13658. 
(146) Dzamba, B. J.; Peters, D. M. Arrangement of Cellular Fibronectin in Noncollagenous Fibrils in Human Fibroblast Cultures. J. Cell Sci. 1991, 100 (Pt 3), 605-612.

(147) Peters, D. M. P.; Chen, Y.; Zardi, L.; Brummel, S. Conformation of Fibronectin Fibrils Varies: Discrete Globular Domains of Type III Repeats Detected. Microsc Microanal 1998, 4 (4), 385-396.

(148) Gudzenko, T.; Franz, C. M. Studying Early Stages of Fibronectin Fibrillogenesis in Living Cells by Atomic Force Microscopy. Mol. Biol. Cell 2015, 26 (18), 3190-3204.

(149) Früh, S. M.; Schoen, I.; Ries, J.; Vogel, V. Molecular Architecture of Native Fibronectin Fibrils. Nat. Commun. 2015, 6, 7275.

(150) Müller, C.; Stamov, D. R.; Werner, C.; Pompe, T. Nanoscale Characterization of Cell Receptors and Binding Sites on Cell-Derived Extracellular Matrices. Ultramicroscopy 2012, 118, 44-52.

(151) Lemmon, C. A.; Weinberg, S. H. Multiple Cryptic Binding Sites Are Necessary for Robust Fibronectin Assembly: An in Silico Study. Sci.Rep. 2017, 7 (1), 1-12.

(152) Raitman, I.; Huang, M. L.; Williams, S. A.; Friedman, B.; Godula, K.; Schwarzbauer, J. E. HeparinFibronectin Interactions in the Development of Extracellular Matrix Insolubility. Matrix Biol. 2017.

(153) Stathakis, N. E.; Mosesson, M. W. Interactions among Heparin, Cold-Insoluble Globulin, and Fibrinogen in Formation of the Heparin-Precipitable Fraction of Plasma. J. Clin. Invest. 1977, 60 (4), 855-865.

(154) Richter, H.; Wendt, C.; Hormann, H. Aggregation and Fibril Formation of Plasma Fibronectin by Heparin. Biol Chem Hoppe Seyler 1985, 366 (5), 509-514.

(155) Bentleys, K. L.; Klebes, R. J.; Hurstq, R. E.; Horowitzll, M. Heparin Binding Is Necessary, but Not Sufficient, for Fibronectin Aggregation: A Fluorescence Polarization Study. J. Biol. Chem. 1985, 260 (12), 7250-7256.

(156) Izzard, C. S.; Radinsky, R.; Culp, L. A. Substratum Contacts and Cytoskeletal Reorganization of 
BALB / c 3T3 Cells on a Cell-Binding Fragment and Heparin- Binding Fragments of Plasma Fibronectin. Exp. Cell Res. 1986, 165, 320-336.

(157) Woods, A.; McCarthy, J. B.; Furcht, L. T.; Couchman, J. R. A Synthetic Peptide from the COOHTerminal Heparin-Binding Domain of Fibronectin Promotes Focal Adhesion Formation. Mol. Biol. Cell 1993, 4 (6), 605-613.

(158) Kapila, Y. L.; Wang, S.; Johnson, P. W. Mutations in the Heparin Binding Domain of Fibronectin in Cooperation with the V Region Induce Decreases in pp125(FAK) Levels plus ProteoglycanMediated Apoptosis via Caspases. J. Biol. Chem. 1999, 274 (43), 30906-30913.

(159) Bloom, L.; Ingham, K. C.; Hynes, R. O. Fibronectin Regulates Assembly of Actin Filaments and Focal Contacts in Cultured Cells via the Heparin-Binding Site in Repeat III13. Mol. Biol. Cell 1999, $10(5), 1521-1536$.

(160) Woods, A.; Longley, R. L.; Tumova, S.; Couchman, J. R. Syndecan-4 Binding to the High Affinity Heparin-Binding Domain of Fibronectin Drives Focal Adhesion Formation in Fibroblasts. Arch Biochem Biophys 2000, 374 (1), 66-72.

(161) Lin, F.; Ren, X. D.; Doris, G.; Clark, R. A. F. Three-Dimensional Migration of Human Adult Dermal Fibroblasts from Collagen Lattices into Fibrin/fibronectin Gels Requires Syndecan-4 Proteoglycan. J. Invest. Dermatol. 2005, 124 (5), 906-913.

(162) Mohri, H.; Tanabe, J.; Katoh, K.; Okubo, T. Identification of a Novel Binding Site to the Integrin alphaIIbbeta3 Located in the C-Terminal Heparin-Binding Domain of Human Plasma Fibronectin. J Biol Chem 1996, 271 (26), 15724-15728.

(163) Haugen, P.; Letourneau, P.; Drake, S.; LT. A Cell-Surface Heparan Sulfate Proteoglycan Mediates Neural Cell Adhesion and Spreading on \&hellip; J. Neurosci. 1992, 12 (July), 2597-1608.

(164) Huebsch, J. C.; McCarthy, J. B.; Diglio, C. A.; Mooradian, D. L. Endothelial Cell Interactions With Synthetic Peptides From the Carboxyl-Terminal Heparin-Binding Domains of Fibronectin. Circ. 
(165) Viji, R. I.; Kumar, V. B. S.; Kiran, M. S.; Sudhakaran, P. R. Angiogenic Response of Endothelial Cells to Heparin-Binding Domain of Fibronectin. Int. J. Biochem. Cell Biol. 2008, 40 (2), 215-226.

(166) Stepp, M. A.; Daley, W. P.; Bernstein, A. M.; Pal-Ghosh, S.; Tadvalkar, G.; Shashurin, A.; Palsen, S.; Jurjus, R. A.; Larsen, M. Syndecan-1 Regulates Cell Migration and Fibronectin Fibril Assembly. Exp. Cell Res. 2010, 316 (14), 2322-2339.

(167) Saunders, S.; Bernfield, M. Cell Surface Proteoglycan Binds Mouse Mammary Epithelial Cells to Fibronectin and Behaves as a Receptor for Interstitial Matrix. J. Cell Biol. 1988, 106 (2), 423-430.

(168) Dalton, B. a; McFarland, C. D.; Underwood, P. a; Steele, J. G. Role of the Heparin Binding Domain of Fibronectin in Attachment and Spreading of Human Bone-Derived Cells. J. Cell Sci. 1995, 108 ( Pt 5, 2083-2092.

(169) McCarthy, J. B.; Chelberg, M. K.; Mickelson, D. J.; Furcht, L. T. Localization and Chemical Synthesis of Fibronectin Peptides with Melanoma Adhesion and Heparin Binding Activities. Biochemistry 1988, 27, 1380-1388.

(170) McCarthy, J. B.; Skubitz, A. P. N.; Zhao, Q.; Yi, X.; Mickelson, D. J.; Klein, D. J.; Furcht, L. T. RGD-Independent Cell Adhesion to the Carboxy-Terminal Heparin-Binding Fragment of Fibronectin Involves Heparin-Dependent and -Independent Activities. J. Cell Biol. 1990, 110 (3), 777-787.

(171) Drake, S. L.; Klein, D. J.; Mickelson, D. J.; Oegema, T. R.; Furcht, L. T.; McCarthy, J. B.; Drake, S. L.; Klein, D. J.; Mickelson, D. J.; Oegema, T. R.; et al. Cell Surface PhosphatidylinositolAnchored Heparan Sulfate Proteoglycan Initiates Mouse Melanoma Cell Adhesion to a FibronectinDerived, Heparin-Binding Synthetic Peptide. J. Cell Biol. 1992, 117 (6), 1331-1341.

(172) Mostafavi-Pour, Z.; Askari, J. A.; Whittard, J. D.; Humphries, M. J. Identification of a Novel Heparin-Binding Site in the Alternatively Spliced IIICS Region of Fibronectin: Roles of Integrins 
and Proteoglycans in Cell Adhesion to Fibronectin Splice Variants. Matrix Biol. 2001, 20 (1), $63-$ 73.

(173) Haugen, P. K.; McCarthy, J. B.; Skubitz, A. P. N.; Furcht, L. T.; Letourneau, P. C. Recognition of the A Chain Carboxy-Terminal Heparin Binding Region of Fibronectin Involves Multiple Sites: Two Contiguous Sequences Act Independently to Promote Neural Cell Adhesion. J. Cell Biol. 1990, 111 (6 I), 2733-2745.

(174) Yoneda, J.; Saiki, I.; Igarashi, Y.; Kobayashi; Hideo; Fujii, H.; Ishizaki, Y.; Kimizuka, F.; Kato, I.; Azuma, I. Role of the Heparin-Binding Domain of Chimeric Peptides Derived from Fibronectin in Cell Spreading and Motility. Exp. Cell Res. 1995, 217, 169-179.

(175) Kusano, Y.; Oguri, K.; Nagayasu, Y.; Munesue, S.; Ishihara, M.; Saiki, I.; Yonekura, H.; Yamamoto, H.; Okayama, M. Participation of Syndecan 2 in the Induction of Stress Fiber Formation in Cooperation with Integrin $\alpha 5 \beta 1$ : Structural Characteristics of Heparan Sulfate Chains with Avidity to COOH-Terminal Heparin-Binding Domain of Fibronectin. Exp. Cell Res. 2000, 256 (2), 434-444.

(176) Zhang, Y.; Lu, H.; Dazin, P.; Kapila, Y. Functional Differences between Integrin $\alpha 4$ and Integrins $\alpha 5 / \alpha v$ in Modulating the Motility of Human Oral Squamous Carcinoma Cells in Response to the V Region and Heparin-Binding Domain of Fibronectin. Exp. Cell Res. 2004, 295 (1), 48-58.

(177) Kwon, M. J.; Kim, Y.; Choi, Y.; Kim, S. H.; Park, S.; Han, I.; Kang, D. H.; Oh, E. S. The Extracellular Domain of Syndecan-2 Regulates the Interaction of HCT116 Human Colon Carcinoma Cells with Fibronectin. Biochem. Biophys. Res. Commun. 2013, 431 (3), 415-420.

(178) Mohri, H.; Katoh, K.; Iwamatsu, A.; Okubo, T. The Novel Recognition Site in the C-Terminal Heparin-Binding Domain of Fibronectin by Integrin a4b1 Receptor on HL-60 Cells. Exp. Cell Res. 1996, $222(2), 326-332$.

(179) Liao, Y.-F.; Gotwals, P. J.; Koteliansky, V. E.; Sheppard, D.; Van De Water, L. The EIIIA Segment of Fibronectin Is a Ligand for Integrins $\alpha_{9} \beta_{1}$ and $\alpha_{4} \beta_{1}$ Providing a Novel Mechanism for 
(180) Ejim, O. S.; Blunn, G. W.; Brown, R. A. Production of Artificial-Orientated Mats and Strands from Plasma Fibronectin: A Morphological Study. Biomaterials 1993, 14 (10), 743-748.

(181) Mitsi, M.; Handschin, S.; Gerber, I.; Schwartländer, R.; Klotzsch, E.; Wepf, R.; Vogel, V. The Ultrastructure of Fibronectin Fibers Pulled from a Protein Monolayer at the Air-Liquid Interface and the Mechanism of the Sheet-to-Fiber Transition. Biomaterials 2015, 36, 66-79.

(182) Spatz, J. P.; Ulmer, J.; Geiger, B. Force-Induced Fibronectin Fibrillogenesis in Vitro. Soft Matter 2008, 4 (10), 1998-2007.

(183) Feinberg, A. W.; Parker, K. K. Surface-Initiated Assembly of Protein Nanofabrics. Nano Lett. 2010, $10(6), 2184-2191$.

(184) Mnatsakanyan, H.; Rico, P.; Grigoriou, E.; Candelas, A. M.; Rodrigo-Navarro, A.; SalmeronSanchez, M.; Sabater I Serra, R. Controlled Assembly of Fibronectin Nanofibrils Triggered by Random Copolymer Chemistry. ACS Appl. Mater. Interfaces 2015, 7 (32), 18125-18135.

(185) Hocking, D. C.; Sottile, J.; McKeown-Longo, P. J. Fibronectin's III-1 Module Contains a Conformation-Dependent Binding Site for the Amino-Terminal Region of Fibronectin. J. Biol. Chem. 1994, 269 (29), 19183-19191.

(186) Peters, D. M. P.; Chen, Y.; Zardi, L.; Brummel, S. Conformation of Fibronectin Fibrils Varies: Discrete Globular Domains of Type III Repeats Detected. Microsc Microanal 1998, 4 (4), 385-396.

(187) Ingham, K. C.; Brew, S. A.; Huff, S.; Litvinovich, S. V. Cryptic Self-Association Sites in Type III Modules of Fibronectin. J. Biol. Chem. 1997, 272 (3), 1718-1724.

(188) Morla, A.; Zhang, Z.; Ruoslahti, E. Superfibronectin Is a Functionally Distinct Form of Fibronectin. Nature 1994, 367 (6459), 193-196.

(189) Pasqualini, R.; Bourfoulous, S.; Koivunen, E.; Woods, V. L.; Ruoslahti, E. A Polymeric Form of 
Fibronectin Has Antimetastatic Effects against Multiple Tumor Types. Nat Med 1996, 2 (11), 11971203.

(190) Yi, M.; Ruoslahti, E. A Fibronectin Fragment Inhibits Tumor Growth, Angiogenesis, and Metastasis. Proc. Natl. Acad. Sci. U. S. A. 2001, 98 (2), 620-624.

(191) Yi, M.; Sakai, T.; Fassler, R.; Ruoslahti, E. Antiangiogenic Proteins Require Plasma Fibronectin or Vitronectin for in Vivo Activity. Proc. Natl. Acad. Sci. U.S. A. 2003, 100 (20), 11435-11438.

(192) Ohashi, T.; Erickson, H. P. Domain Unfolding Plays a Role in Superfibronectin Formation. J. Biol. Chem. 2005, 280 (47), 39143-39151.

(193) Stine, J. M.; Sun, Y.; Armstrong, G.; Bowler, B. E.; Briknarová, K. Structure and Unfolding of the Third Type III Domain from Human Fibronectin. Biochemistry 2015, 54 (44), 6724-6733.

(194) Stine, J. M.; Ahl, G. J. H.; Schlenker, C.; Rusnac, D. V.; Briknarová, K. The Interaction between the Third Type III Domain from Fibronectin and Anastellin Involves $\beta$-Strand Exchange. Biochemistry 2017, $56(35), 4667-4675$.

(195) Ohashi, T.; Erickson, H. P. Fibronectin Aggregation and Assembly: The Unfolding of the Second Fibronectin Type III Domain. J. Biol. Chem. 2011, 286 (45), 39188-39199.

(196) Briknarová, K.; Åkerman, M. E.; Hoyt, D. W.; Ruoslahti, E.; Ely, K. R. Anastellin, an FN3 Fragment with Fibronectin Polymerization Activity, Resembles Amyloid Fibril Precursors. J. Mol. Biol. 2003, $332(1), 205-215$.

(197) Schwarz-linek, U.; Werner, J. M.; Pickford, A. R.; Gurusiddappa, S.; Kim, J. H.; Pilka, E. S.; Briggs, J. A. G.; Gough, T. S.; Höök, M.; Campbell, I. D.; et al. Pathogenic Bacteria Attach to Human Fibronectin through a Tandem Beta-Zipper. Nature 2003, 423, 5699-5702.

(198) Litvinovich, S. V; Brew, S. A.; Aota, S.; Akiyama, S. K.; Haudenschild, C.; Ingham, K. C. Formation of Amyloid-like Fibrils by Self-Association of a Partially Unfolded Fibronectin Type III Module. J. 
(199) Gee, E. P. S.; Yü Ksel, D.; Stultz, C. M.; Ingber, D. E. SLLISWD Sequence in the 10FNIII Domain Initiates Fibronectin Fibrillogenesis. J. Biol. Chem. 2013, 288 (29), 21329-21340.

(200) Bascetin, R.; Admane, K.; Agniel, R.; Boudou, T.; Doussineau, T.; Antoine, R.; Gallet, O.; LeroyDudal, J.; Vendrely, C. Amyloid-like Aggregates Formation by Blood Plasma Fibronectin. Int. J. Biol. Macromol. 2017, 97, 733-743.

(201) Bascetin, R.; Blay, L.; Kellouche, S.; Carreiras, F.; Picot, C.; Briand, M.; Agniel, R.; Gallet, O.; Vendrely, C.; Leroy-Dudal, J. Fibronectin Amyloid-like Aggregation Alters Its Extracellular Matrix Incorporation and Promotes a Single and Sparsed Cell Migration. Exp. Cell Res. 2018.

(202) Bush, A. I. The Metallobiology of Alzheimer's Disease. Trends Neurosci. 2003, 26 (4), 207-214.

(203) Frederickson, C. J.; Koh, J. Y.; Bush, A. I. The Neurobiology of Zinc in Health and Disease. Nat. Rev. Neurosci. 2005, 6 (6), 449-462.

(204) Mantyh, P. W.; Ghilardi, J. R.; Rogers, S.; DeMaster, E.; Allen, C. J.; Stimson, E. R.; Maggio, J. E. Aluminum, Iron, and Zinc Ions Promote Aggregation of Physiological Concentrations of BetaAmyloid Peptide. J. Neurochem. 1993, 61, 1171-1174.

(205) Esler, W. P.; Stimson, E. R.; Jennings, J. M.; Ghilardi, J. R.; Mantyh, P. W.; Maggio, J. E. ZincInduced Aggregation of Human and Rat Beta-Amyloid Peptides in Vitro. J Neurochem 1996, 66 (2), $723-732$.

(206) Arispe, N.; Pollard, H. B.; Rojas, E. Zn2+ Interaction with Alzheimer Amyloid Beta Protein Calcium Channels. Proc. Natl. Acad.Sci. U. S. A. 1996, 93, 1710-1715.

(207) Lovell, M. A.; Robertson, J. D.; Teesdale, W. J.; Campbell, J. L.; Markesbery, W. R. Copper, Iron and Zinc in Alzheimer's Disease Senile Plaques. J. Neurol. Sci. 1998, 158 (1), 47-52.

(208) Danielsson, J.; Pierattelli, R.; Banci, L.; Gräslund, A. High-Resolution NMR Studies of the Zinc- 
(209) Lee, M. C.; Yu, W. C.; Shih, Y. H.; Chen, C. Y.; Guo, Z. H.; Huang, S. J.; Chan, J. C. C.; Chen, Y. R. Zinc Ion Rapidly Induces Toxic, off-Pathway Amyloid- $\beta$ Oligomers Distinct from Amyloid- $\beta$ Derived Diffusible Ligands in Alzheimer's Disease. Sci. Rep. 2018, 8 (1), 1-16.

(210) McDonald, J. A. Extracellular Matrix Assembly. Ann Rev Cell Biol 1988, 4, 183-207.

(211) Vuento, M.; Vartio, T.; Saraste, M.; von Bonsdorff, C. H.; Vaheri, A. Spontaneous and PolyamineInduced Formation of Filamentous Polymers from Soluble Fibronectin. Eur J Biochem 1980, 105 $(1), 33-42$.

(212) Llopis-Hernandez, V.; Rico, P.; Moratal, D.; Altankov, G.; Salmeron-Sanchez, M. Role of MaterialDriven Fibronectin Fibrillogenesis in Cell Differentiation. Biomaterials 2011, 32 (8), 2099-2105.

(213) Llopis-Hernández, V.; Cantini, M.; González-García, C.; Cheng, Z. A.; Yang, J.; Tsimbouri, P. M.; García, A. J.; Dalby, M. J.; Salmerón-Sánchez, M. Material-Driven Fibronectin Assembly for HighEfficiency Presentation of Growth Factors. Sci. Adv. 2016, 2 (8), 1-10.

(214) Moulisová, V.; Gonzalez-García, C.; Cantini, M.; Rodrigo-Navarro, A.; Weaver, J.; Costell, M.; Sabater i Serra, R.; Dalby, M. J.; García, A. J.; Salmerón-Sánchez, M. Engineered Microenvironments for Synergistic VEGF - Integrin Signalling during Vascularization. Biomaterials 2017, 126, 61-74.

(215) Sun, Y.; Jallerat, Q.; Szymanski, J. M.; Feinberg, A. W. Conformal Nanopatterning of Extracellular Matrix Proteins onto Topographically Complex Surfaces. Nat Methods 2015, 12 (2), 134-136.

(216) Duffy, R. M.; Sun, Y.; Feinberg, A. W. Understanding the Role of ECM Protein Composition and Geometric Micropatterning for Engineering Human Skeletal Muscle. Ann. Biomed. Eng. 2016, 44 (6), 2076-2089.

(217) Palchesko, R. N.; Szymanski, J. M.; Sahu, A.; Feinberg, A. W. Shrink Wrapping Cells in a Defined 
Extracellular Matrix to Modulate the Chemo-Mechanical Microenvironment. Cell Mol Bioeng 2014, 7 (3), 355-368.

(218) Brown, R. A.; Blunn, G. W.; Ejim, O. S. Preparation of Orientated Fibrous Mats from Fibronectin: Composition and Stability. Biomaterials 1994, 15 (6), 457-464.

(219) Ahmed, Z.; Underwood, S.; Brown, R. A. A. Nerve Guide Material Made from Fibronectin: Assessment of in Vitro Properties. Tissue Eng. 2003, 9 (2), 219-231.

(220) Whitworth, I. H.; Brown, R. A.; Dore, C.; Green, C. J.; Terenghi, G. Orientated Mats Of Fibronectin Material For Use In Peripheral As A Conduit. J Hand Surg Br 1995, 20 (B), 429-436.

(221) King, V. R.; Henseler, M.; Brown, R. A.; Priestley, J. V. Mats Made from Fibronectin Support Oriented Growth of Axons in the Damaged Spinal Cord of the Adult Rat. Exp. Neurol. 2003, 182 (2), 383-398.

(222) Phillips, J. B.; King, V. R.; Ward, Z.; Porter, R. A.; Priestley, J. V.; Brown, R. A. Fluid Shear in Viscous Fibronectin Gels Allows Aggregation of Fibrous Materials for CNS Tissue Engineering. Biomaterials 2004, 25 (14), 2769-2779.

(223) King, V. R.; Phillips, J. B.; Hunt-Grubbe, H.; Brown, R.; Priestley, J. V. Characterization of NonNeuronal Elements within Fibronectin Mats Implanted into the Damaged Adult Rat Spinal Cord. Biomaterials 2006, 27 (3), 485-496.

(224) King, V. R.; Hewazy, D.; Alovskaya, A.; Phillips, J. B.; Brown, R. A.; Priestley, J. V. The Neuroprotective Effects of Fibronectin Mats and Fibronectin Peptides Following Spinal Cord Injury in the Rat. Neuroscience 2010, 168 (2), 523-530.

(225) Underwood, S.; Afoke, A.; Brown, R. A.; MacLeod, A. J.; Ayazi Shamlou, P.; Dunnill, P. Wet Extrusion of Fibronectin-Fibrinogen Cables for Application in Tissue Engineering. Biotechnol. Bioeng. 2001, 73 (4), 295-305. 
(226) Zhou, N. F.; Pethica, B. A. Monolayers of Human-Plasma Fibronectin at the Air-Water-Interface. Langmuir 1986, 2 (1), 47-50.

(227) Vogel, V. Fibronectin in a Surface-Adsorbed State - Insolubilization and Self-Assembly. Proteins Interfaces II 1995, 602, 505-518.

(228) Klotzsch, E.; Smith, M. L.; Kubow, K. E.; Muntwyler, S.; Little, W. C.; Beyeler, F.; Gourdon, D.; Nelson, B. J.; Vogel, V. Fibronectin Forms the Most Extensible Biological Fibers Displaying Switchable Force-Exposed Cryptic Binding Sites. Proc. Natl. Acad. Sci. U. S. A. 2009, 106 (43), $18267-18272$.

(229) Rossier, O.; Cuvelier, D.; Borghi, N.; Puech, P. H.; Derenyi, I.; Buguin, A.; Nassoy, P.; BrochardWyart, F. Giant Vesicles under Flows: Extrusion and Retraction of Tubes. Langmuir 2003, 19 (3), $575-584$.

(230) Evans, E.; Yeung, A. Hidden Dynamics in Rapid Changes of Bilayer Shape. Chem. Phys. Lipids 1994, $73(1-2), 39-56$.

(231) Campioni, S.; Carret, G.; Jordens, S.; Nicoud, L.; Mezzenga, R.; Riek, R. The Presence of an Air Water Interface Affects Formation and Elongation of $\alpha$-Synuclein Fibrils. J. Am. Chem. Soc. 2014, $136,2866-2875$.

(232) Little, W. C.; Smith, M. L.; Ebneter, U.; Vogel, V. Assay to Mechanically Tune and Optically Probe Fibrillar Fibronectin Conformations from Fully Relaxed to Breakage. Matrix Biol 2008, 27 (5), 451461.

(233) Mitsi, M.; Schulz, M. M. P.; Gousopoulos, E.; Ochsenbein, A. M.; Detmar, M.; Vogel, V. Walking the Line: A Fibronectin Fiber-Guided Assay to Probe Early Steps of (Lymph) Angiogenesis. PLoS One 2015, 10 (12). 


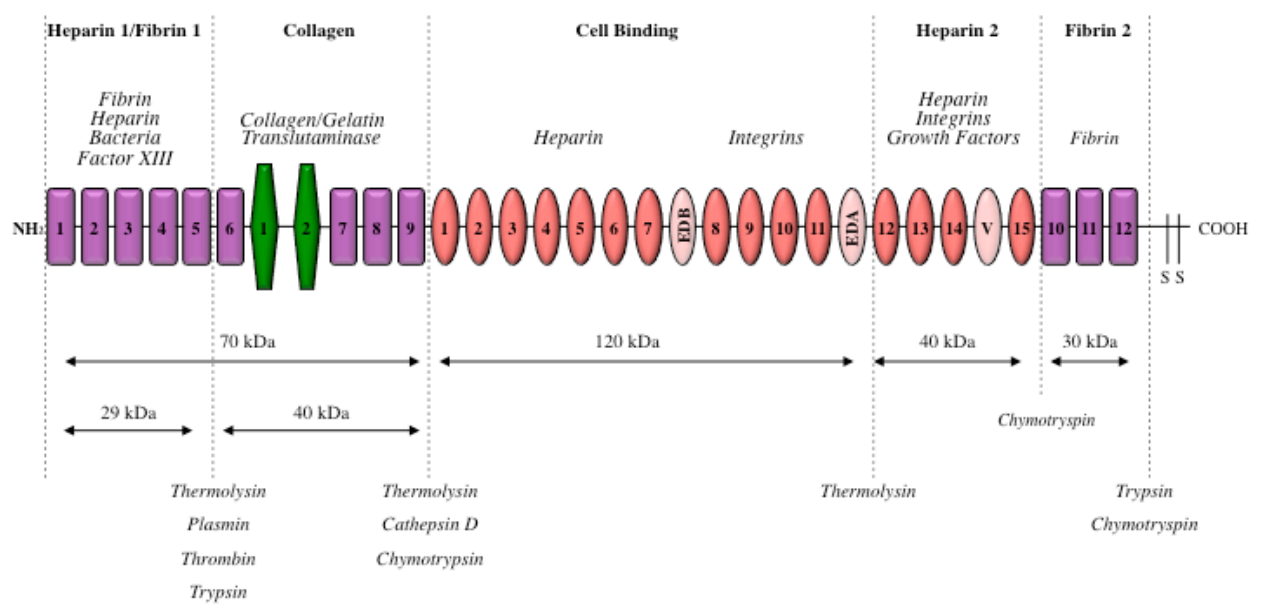

